\title{
Review
}

\section{Silicon stable isotope fractionation between metal and silicate at high-pressure, high-temperature conditions as a tracer of planetary core formation}

\section{J. Kempl ${ }^{1,2, *}$, P.Z. Vroon ${ }^{1}$, B. van der Wagt ${ }^{1}$, E. Zinngrebe ${ }^{3}$, D.J. Frost ${ }^{4} \&$ W. van Westrenen ${ }^{1}$}

1 Faculty of Earth and Life Sciences, Vrije Universiteit University Amsterdam, De Boelelaan 1085, 1081HV Amsterdam, the Netherlands

2 Faculty of Civil Engineering and Geosciences, Delft University of Technology, Stevinweg 1, 2628CN Delft, the Netherlands

3 Ceramics Research Center, Tata Steel IJmuiden, Building Code 3J-22, P.0. Box 1000, 1970 CA IJmuiden, the Netherlands

4 Bayerisches Geoinstitut, University of Bayreuth, D-95440 Bayreuth, Germany

* Corresponding author. Email: w.van.westrenen@vu.nl

Manuscript received: 24 July 2014, accepted: 17 December 2015

\section{Abstract}

The largest differentiation event in Earth and other terrestrial planets was the high-pressure, high-temperature process of metal core segregation from a silicate mantle. The abundant element silicon ( $\mathrm{Si}$ ) can be partially sequestered into the metallic core during metal-silicate differentiation, depending on pressure, temperature and planetary oxidation state. Knowledge of the Si content of a planet's core can constrain the conditions of core formation, but in the absence of direct samples from planetary cores, quantifying core Si content is challenging. One relatively new tool to study core formation in terrestrial planets is based on combining measurements of the $\mathrm{Si}$ stable isotopic composition of planetary crust and mantle samples with measurements of the Si stable isotope fractionation between metal and silicate at high-temperature and high-pressure conditions. In this study we present the results of a small set of high-pressure, high-temperature (HPT) experiments and combine these with a review of literature data to investigate how the $\mathrm{Si}$ isotope fractionation behaviour between metal and silicate varies as a function specifically of experimental run time and temperature. We show that although there is no debate about the sign of fractionation, absolute values for Si isotope fractionation between metal and silicate are difficult to constrain because the experimental database remains incomplete, and because $\mathrm{Si}$ isotopic measurements of metals in particular suffer from the absence of a true inter-laboratory comparison. We conclude that in order to derive accurate quantitative estimates of the $\mathrm{Si}$ content of the core of the Earth or other planets a wide range of additional experiments will be required.

Keywords: Core formation, HPT experiments, metal-silicate systems, Si isotope fractionation

\section{Introduction}

\section{Planetary accretion and metallic core formation}

Seismological data show that currently the Earth consists of a dense inner solid and outer liquid metallic core (Fig. 1), surrounded by a silicate shell (bulk silicate earth, BSE) comprising a mantle and a crust (e.g. Birch, 1952). This large-scale internal differentiation occurred within the first 100 million years of the formation of the solar system and the Earth, and is linked to early planetary accretion processes.
Planetary accretion proceeds by collisions of planetesimals and smaller planetary bodies on a timescale of thousands of years in the terrestrial planet zone of our solar system. Larger planetesimals grow by gravitationally sweeping up smaller ones, leading to larger bodies growing more rapidly than the smaller planetesimals. This so-called 'runaway growth process' (e.g. Kortenkamp et al., 2001; Inaba et al., 2001) led to the formation of several tens of Moon- to Mars-sized planetary embryos in the terrestrial planet zone. Final accretion of today's terrestrial planets took place through large impact events (e.g. Wetherill, 1985; Stevenson, 1990; Chambers, 2004; Wood \& Halliday, 2005). 


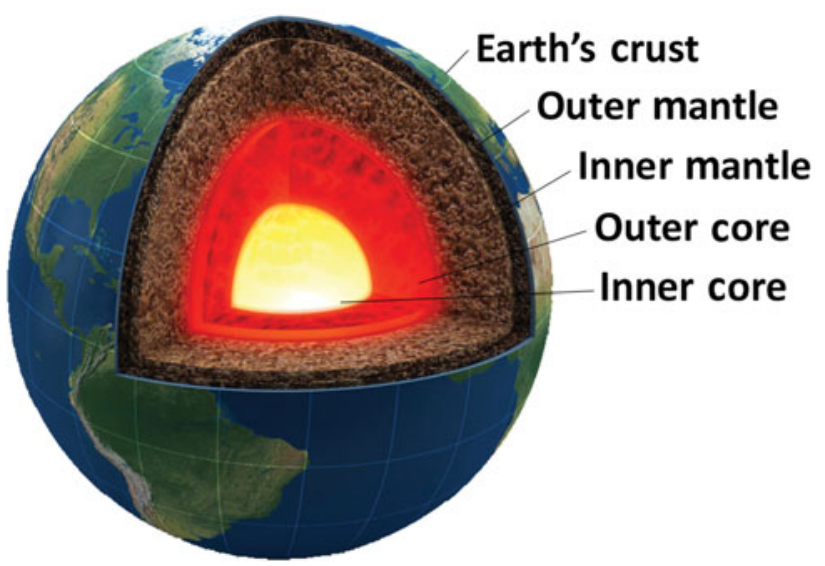

Fig. 1. Currently, the Earth is differentiated into a silicate shell (BSE) and an inner solidified and outer liquefied metallic core. The core-mantle boundary (CMB) is located between the outer metallic portion and the inner part of the silicate shell (inner mantle).

The kinetic energy of small and large collisions is converted into thermal energy. The build-up of heat, in combination with heat production through natural radioactive decay, led to widespread melting and the formation of deep magma oceans on most if not on all the terrestrial planets and the Moon (e.g. Yoshino et al., 2003; Rubie et al., 2003; Elkins-Tanton, 2012; Rai \& Van Westrenen, 2013, 2014). As a consequence of large-scale melting, the planets, including the primitive Earth, differentiated into a dense metallic core and a siliceous mantle. Measurements comparing the tungsten isotopic compositions of chondritic meteorites and BSE indicate that the main stage of terrestrial core segregation probably took place between 30 and $60 \mathrm{Ma}$ after the formation of the solar system (e.g. Yin et al., 2002; Burkhardt et al., 2008).

\section{The geochemical and geophysical signature of the Earth and its core}

Since it is impossible to obtain samples from the Earth's deepest interior, information on the Earth's bulk chemical composition and its core can only be acquired indirectly, by investigating meteorites and by sampling the accessible parts of the silicate Earth. Additional indirect evidence can be gained from seismic observations. These geochemical and geophysical investigations yield models for the composition of the BSE and the bulk earth (BE), from which the chemical composition of the core can be estimated using simple mass balance.

Chemical composition of BSE and BE. Accretion and planetary differentiation have both influenced element abundances in the Earth's mantle. Based on element concentrations of the Earth's mantle derived from mantle xenoliths and Mid-Ocean Ridge Basalt analyses (e.g. Allègre et al., 1995;

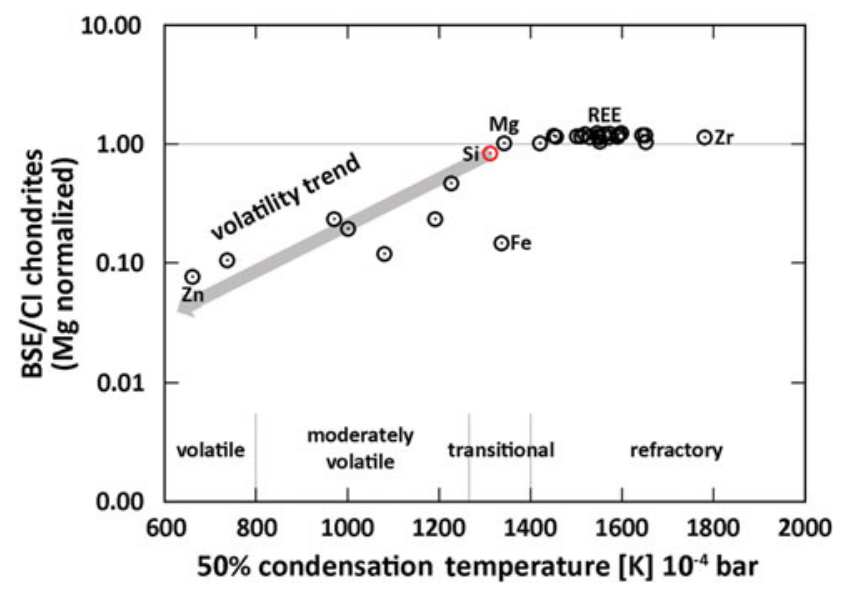

Fig. 2. The abundance of lithophile elements (plus iron) in BSE normalised to CI chondrites and Mg (BSE abundances from McDonough, 2003; CI abundances from Lodders, 2003). BSE depletions of elements to abundances below the estimate for bulk Earth are assumed to be due to segregation of these elements into the Earth's core (e.g. iron). Relative to the magnesium concentration in CI chondrites and BSE, silicon also shows a slight depletion in the silicate portion of the Earth.

McDonough \& Sun, 1995), it was found that BSE for many elements is chemically related to carbonaceous (CI) chondrites - the most primitive chondritic meteorites in our solar system, which are believed to form the main building blocks of Earth.

Geochemically distinct groups of elements show different degrees of depletion in the Earth's mantle compared to the composition of these CI chondrites. This observed depletion appears to depend in part on the elemental condensation temperatures (e.g. Lodders, 2003). Elements including Zr, Mg, and rare earth elements are lithophile and prefer to partition into silicates over metallic or sulphide phases. They are also non-volatile or refractory elements, and their relative abundances in BSE are comparable to their relative abundances in CI chondrites. These elements were not removed from the mantle by differentiation processes and were not lost before or during Earth formation by volatilisation. In contrast, more volatile lithophile elements are depleted from the Earth's mantle relative to CI chondrites either as a result of partial condensation from the solar nebula or due to their volatility during high-temperature planetary accretion processes.

The $50 \%$ condensation temperature of an element can approximate its volatility degree. By definition, this is the temperature at which half of the number of atoms of the element reside in a solid phase and half in the gas phase. Fig. 2 shows a simplified illustration of the observed abundances of lithophile elements and iron in the Earth's mantle, normalised to CI chondrite element abundances and $\mathrm{Mg}$, versus their 50\% condensation temperatures determined thermodynamically (data from McDonough, 2003; Lodders, 2003). The trend of decreasing abundance of moderately lithophile elements with decreasing 


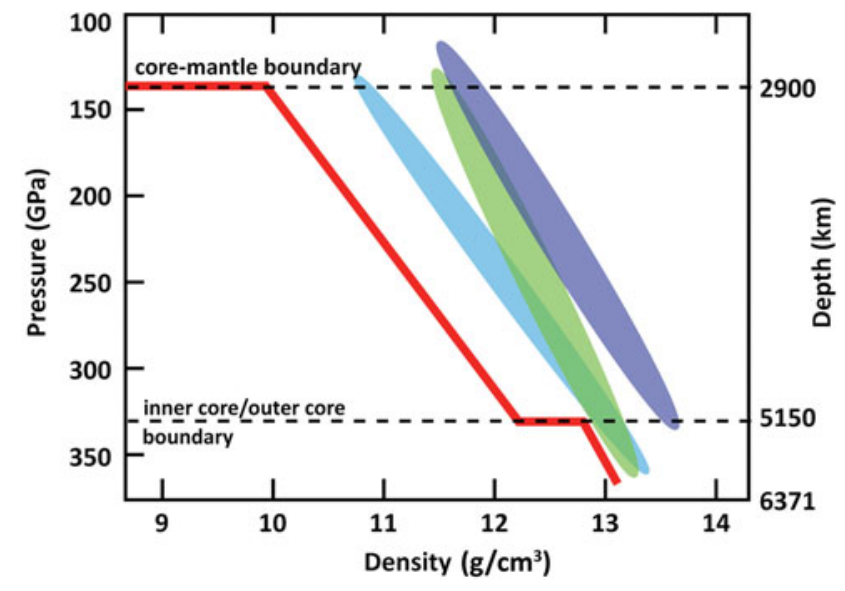

Fig. 3. Density vs depth plot of the outer Earth's core region $(2900-5150 \mathrm{~km}$ from Earth's surface). The comparison between measured core density (red line) and experimentally investigated density of pure Fe-Ni alloys at HPT conditions illustrates the core density deficit (CDD; blue field for iron-nickel melt; purple field for a solidified iron-nickel composition; green field for a partially molten iron-nickel composition; modified after Li \& Fei, 2003).

$50 \%$ condensation temperature is called the Earth's volatility trend. With respect to the composition of the core it is assumed that the solid grey line in Fig. 2 defines the composition of the BE. The grey arrow at the left-hand side of Fig. 2 indicates the Earth's volatility trend.

Geophysical constraints on core composition. The presence of a core-mantle boundary (CMB) in the Earth was first suspected at a depth of $2900 \mathrm{~km}$ (Figs 1 and 3) by Oldham (1906) and was subsequently confirmed on the basis of seismic measurements and calculations by Gutenberg (1914) and Jeffreys (1935). Temperature estimates of today's Earth's core range from 4000 to $7000 \mathrm{~K}$ and pressures vary between 136 and $364 \mathrm{GPa}$ from the CMB to the Earth's centre. The inner core consists of a solidified iron-nickel alloy. A primary feature of Earth's present-day liquid outer core is its so-called core density deficit (CDD), referring to the seismological observation that the outer core density is between $2.5 \%$ and $10 \%$ lower than expected for a molten iron-nickel alloy (Fig. 3; Birch, 1952, 1964; Anderson \& Isaak, 2002).

The CDD can be explained by the incorporation of one or more light elements into the core (e.g. Poirier, 1994; Javoy, 1999; Dreibus \& Palme, 1996; Li \& Fei, 2003). In addition to sulfur (e.g. Brett, 1984), oxygen (e.g. Corgne et al., 2009), hydrogen (e.g. Okuchi, 1997) and carbon (e.g. Wood, 1993; Dasgupta \& Walker, 2008), silicon has been proposed as a 'key' light element in the outer Earth's core (e.g. MacDonald \& Knopoff, 1958; Birch, 1964; Ringwood, 1966; Tuff et al., 2011). The Earth is not unique in having light elements in its core: light elements are also known to be present in the cores of the Moon (e.g. Rai \& Van Westrenen, 2014), Mars (e.g. Rai \& Van Westrenen, 2013) and Mercury (e.g. Dumberry \& Rivoldini, 2014; Knibbe \& Van

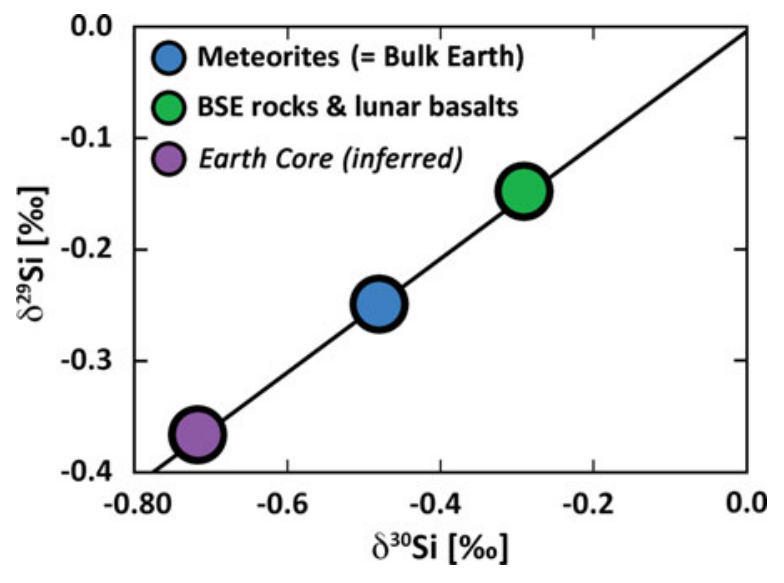

Fig. 4. Three-isotope diagram showing average isotope signatures of undifferentiated meteorites, BSE and lunar basalts (data from Georg et al., 2007; Fitoussi et al., 2009; Ziegler et al., 2010; Chakrabarti \& Jacobsen, 2010; Armytage et al. 2011, 2012). The observed mass difference between Earth's building blocks (meteorites) and BSE is explained by Si equilibrium isotope fractionation between metal and silicate at high-temperature conditions. If Si would be a light element in the Earth's core, the metal would concentrate the light isotope fraction.

Westrenen, 2015), as well as differentiated asteroids such as Vesta (e.g. Steenstra et al., 2015). The nature and abundance of light elements in a planetary core provide a fingerprint for planetary core formation conditions, and therefore provide constraints on early planetary evolution. For example, Si can only be incorporated into metal at oxygen-poor (highly reducing) conditions - conditions that are not present in the Earth today. If $\mathrm{Si}$ is present in Earth's core, the Earth must have been much less oxygen-rich when its core formed than it is today.

\section{The role of Si stable isotopes}

Due to the advent of multi-collector (MC) ICPMS techniques, it has become possible in recent years to approach the specific question of $\mathrm{Si}$ incorporation into the core of the Earth and other planetary bodies by studying the distribution of $\mathrm{Si}$ stable isotopes $\left({ }^{28} \mathrm{Si},{ }^{29} \mathrm{Si}\right.$ and $\left.{ }^{30} \mathrm{Si}\right)$ between metals and silicates, either by comparing isotopic signatures of terrestrial and extra-terrestrial silicate samples or by measuring their distribution in coexisting metal and silicate phases equilibrated in experiments simulating conditions of core formation. Isotopegeochemical investigations of terrestrial mantle rocks, as well as lunar samples (summarised in Fig. 4), show slightly higher $\delta^{30} \mathrm{Si}$ $\left(\delta^{30} \mathrm{Si}=\left[\left(\left({ }^{30} \mathrm{Si} /{ }^{28} \mathrm{Si}_{\text {sample }}\right) /\left({ }^{30} \mathrm{Si} /{ }^{28} \mathrm{Si}_{\text {standard }}\right)\right)-1\right] \times 1000[\% \mathrm{\%}]\right)$ values than undifferentiated meteorites (Georg et al., 2007; Fitoussi et al., 2009; Ziegler et al., 2010; Chakrabarti \& Jacobsen, 2010; Armytage et al., 2011, 2012; Savage \& Moynier, 2013; see recent compilation by Savage et al., 2014). The average $\delta^{30} \mathrm{Si}$ isotopic signature of terrestrial mantle rocks is estimated to be $-0.29 \%$ o $\pm 0.07 \%$, 2 $\mathrm{SD}$ (Douthitt, 1982; Georg et al. 2007; 
Fitoussi et al., 2009; Ziegler et al., 2010; Savage et al., 2010; Chakrabarti \& Jacobsen, 2010; Armytage et al., 2011, 2012; Savage \& Moynier, 2013; Savage et al., 2014; see Fig. 4). The average $\delta^{30} \mathrm{Si}$ isotopic signature for carbonaceous and ordinary chondrites $\left(\delta^{30} \mathrm{Si}_{\mathrm{CHUR}}\right)$ is $-0.47 \%$ o $\pm 0.06 \%$ (Molini-Velsko et al., 1986; Georg et al., 2007; Fitoussi et al., 2009; Chakrabarti \& Jacobsen, 2010; Armytage et al., 2011, 2012; Fitoussi \& Bourdon, 2012; Savage \& Moynier, 2013; Savage et al., 2014; Fig. 4).

The absolute isotopic difference between $\mathrm{CI}$ chondrites and the BSE of $\Delta^{30} \mathrm{Si}_{\mathrm{BSE}-\mathrm{CHUR}}=0.18 \%$ $\pm 0.06 \%$ (where $\Delta^{30} \mathrm{Si}_{\mathrm{A}-\mathrm{B}}=$ $\delta^{30} \mathrm{Si}_{\mathrm{A}}-\delta^{30} \mathrm{Si}_{\mathrm{B}}$ ) has been explained by equilibrium metal-silicate $\mathrm{Si}$ isotope fractionation at high-temperature and high-pressure (HPT) conditions at reducing oxygen conditions (e.g. Georg et al., 2007; Shahar et al., 2009, 2011; Ziegler et al., 2010; Kempl et al., 2013a; Hin et al., 2014), driven by the different chemical bonding environment of $\mathrm{Si}$ in silicate rocks versus metallic liquid (Schauble et al., 2007; Georg et al., 2007). If $\mathrm{Si}$ isotope fractionation between metal and silicate is an equilibrium process, the heavier isotopes fractionate preferentially into the stiffer bonded phase, in this case the silicate. Heavier $\mathrm{Si}$ isotopes fractionating into the silicate, and lighter isotopes fractionating into the metal was observed in meteorite samples that contain both metal and silicate phases: first in enstatite chondrites, comprising a Si-bearing metal and a silicate phase (Molini-Velsko et al., 1986), and subsequently by Ziegler et al. (2010), who assumed $\mathrm{Si}$ isotope equilibration between metal and silicate in two aubrite meteorites occurred through solidstate diffusion.

If metal-silicate equilibration is the cause of the observed difference between CI chondrites and BSE Si isotopic composition, (1) Si must be present in the Earth's core and (2) the Earth's core $\mathrm{Si}$ isotopic signature must be isotopically lighter than the Si isotopic signature of the BSE (Fig. 4).

\section{Evidence for Si in the Earth's outer core}

Geochemical and geophysical lines of evidence support the hypothesis that $\mathrm{Si}$ is one of the light elements in the outer Earth's core, but uncertainty about its concentration remains substantial. The latest geophysical models suggest that the Earth's core contains up to $4.5 \mathrm{wt} \% \mathrm{Si}$, in addition to significant amounts of oxygen (e.g. Badro et al., 2014). The experimental observation that $\mathrm{Si}$ becomes more siderophile with increasing pressure and temperature conditions and decreasing oxygen fugacity could explain the observed slight depletion of $\mathrm{Si}$ in the silicate portion of the Earth compared to its predicted BSE concentration using the Earth's volatility trend (Fig. 2).

The observed superchondritic $\mathrm{Mg} / \mathrm{Si}$ and $\mathrm{Al} / \mathrm{Si}$ ratios in the primitive upper mantle (e.g. Allègre et al., 1995; Drake \& Righter, 2002) can be reconciled with chondritic models of bulk Earth composition by incorporating approximately $6 \mathrm{wt} \%$ of $\mathrm{Si}$ in the core (e.g. McDonough, 2003).
The experimentally determined element partitioning behaviour of $\mathrm{Si}$ and a range of other siderophile elements suggest the presence of anywhere between 1 and $11 \mathrm{wt} \% \mathrm{Si}$ in the core (e.g. Ricolleau et al., 2011). Although this is qualitatively consistent with cosmochemical arguments, constraints from Si partitioning data are currently not precise enough to distinguish between different core formation scenarios.

Translation of the observed $\mathrm{Si}$ isotope fractionation between the BSE and the Earth's building blocks ( $~ 0.2$ per mille in terms of $\Delta^{30} \mathrm{Si}$ ) into corresponding core $\mathrm{Si}$ concentrations requires knowledge of $\mathrm{Si}$ isotope fractionation factors between silicate and iron metal at HPT conditions. To date, these have mostly been predicted using theoretical calculations (e.g. Georg et al., 2007; Fitoussi et al., 2009; Ziegler et al., 2010; Chakrabarti \& Jacobsen, 2010; Armytage et al., 2011), suggesting that the $\mathrm{Si}$ concentration in the Earth's outer core could comprise between 2.5 and $16.8 \mathrm{wt} \% \mathrm{Si}$ (Armytage et al., 2011), a range that is even larger than the range derived from the Si elemental partitioning data given above (1-11 wt\%; Ricolleau et al., 2011).

\section{The role of HPT experiments}

HPT experimental metal-silicate systems aim to simulate the elemental and/or isotopic distribution between planetary cores and mantles. HPT experiments on the elemental partitioning behaviour of $\mathrm{Si}$ between metal and silicate have shown that $\mathrm{Si}$ becomes more siderophile (iron metal-loving) with increasing pressure and temperature, and decreasing oxygen fugacity (e.g. Kilburn \& Wood, 1997; Gessmann et al., 2001; Malavergne et al., 2004; Wade \& Wood, 2005; Corgne et al., 2009; Tuff et al., 2011).

Experimental studies on $\mathrm{Si}$ isotope fractionation between metal and silicate were carried out by Shahar et al. (2009, 2011) at pressures of 1 and $7 \mathrm{GPa}$, and temperatures between 1800 and $2200^{\circ} \mathrm{C}$. Kempl et al. (2013a) did experiments at 9 GPa and $\sim 2150^{\circ} \mathrm{C}$. Kempl et al. (2013b) approached the study of $\mathrm{Si}$ isotope fractionation processes at high temperature conditions in an industrial-scale experiment by sampling metal and silicate phases from a blast furnace at Tatasteel IJmuiden, the Netherlands, with maximum temperatures reaching $1600^{\circ} \mathrm{C}$ during sampling. Hin et al. (2014) performed experiments between 0.5 and $1 \mathrm{GPa}$ pressure, and a temperature range between 1450 and $1750^{\circ} \mathrm{C}$.

Here, we review the materials and methods used in these experimental studies, and extend the experimental database by presenting results of metal-silicate $\mathrm{Si}$ isotope fractionation experiments done at pressures of 9, 16 and $25 \mathrm{GPa}$ and temperatures between 2150 and $2300^{\circ} \mathrm{C}$. We assess to what extent the pressure-temperature effects on $\mathrm{Si}$ isotope fractionation can be quantified by combining all available experimental data. Finally, we discuss the implications of our findings for the use of $\mathrm{Si}$ isotopic data to constrain core formation in the Earth and other terrestrial planets. 
Fig. 5. Sample preparation for a pistoncylinder assembly applied in the quick-press piston-cylinder at VU University Amsterdam. $A, B$. Assembly preparation with white $\mathrm{Al}_{2} \mathrm{O}_{3}$ insulation material containing the thermocouple, a corundum disc, the welded Pt capsule with sample material, another $\mathrm{Al}_{2} \mathrm{O}_{3}$ cylinder hosting the sample capsule and the graphite oven surrounded by talc-pyrex glass; c. The sample assembly is put together and set-up on the piston with an insulation paper (light blue). A thermocouple is located close to the sample; $D$. The assembly is ready for the experiment and inserted into the pistoncylinder, where pressure is applied from the bottom.

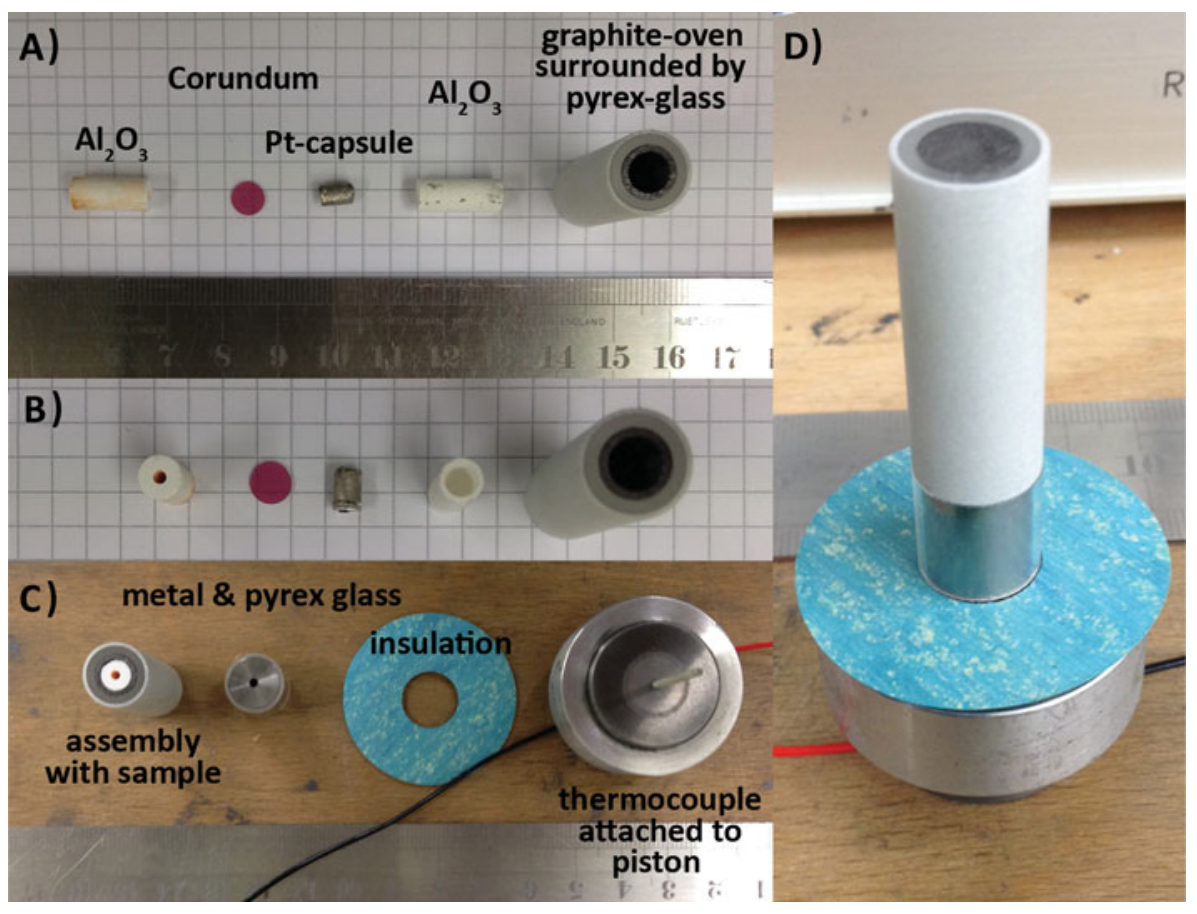

\section{Materials and methods: previously published work}

\section{High-pressure experimental methods}

High-pressure experiments on $\mathrm{Si}$ isotope fractionation have been performed in two different types of apparatus: pistoncylinder presses and multi-anvil presses. A piston-cylinder is a high-pressure apparatus in which several cubic millimetres of sample can be subjected to pressures of up to $4 \mathrm{GPa}$ and temperatures of over $2000^{\circ} \mathrm{C}$. The piston-cylinder was developed by Boyd \& England (1960), initially to investigate thermodynamic phase-equilibria under HPT conditions. Meanwhile a large variety of piston-cylinders exists, all with very similar operational principles: a sample in a noble metal capsule is inserted into a cylindrical assembly (Fig. 5), which consists mainly of insulating ceramic material, a conducting graphite oven and a thermocouple. The assembly is inserted in the centre of a cylindrically shaped, water-cooled pressure plate. Pressure is applied hydraulically to a piston, which compresses the whole assembly against a top-fixed metal plate (an example is shown in Fig. 6). Temperature is controlled by resistive heating of the graphite furnace. 0xygen fugacity can be controlled by surrounding sample materials with buffer materials. In order to study $\mathrm{Si}$ isotope fractionation between metal and silicate, piston-cylinder experiments were run between 0.54 and $1 \mathrm{GPa}$ pressure and in a temperature range between 1450 and $1800^{\circ} \mathrm{C}$ by Shahar et al. $(2009,2011)$ and Hin et al. (2014). The latter study used a rotating piston-cylinder apparatus (Schmidt et al., 2006) that enabled improved density separation of metal and silicate phases.
Pressures above $4 \mathrm{GPa}$ can be reached in a multi-anvil press (e.g. Walker, 1990), in which smaller samples are subjected to higher loads (Fig. 7A). Again samples can be inserted in a noblemetal capsule, which is commonly cold-welded by the pressure of the multi-anvil press. An example of sample preparation is shown in Fig. 7B. Metal-silicate $\mathrm{Si}$ isotope fractionation experiments in multi-anvil presses were previously run at pressures of 7 and $9 \mathrm{GPa}$ and between 2000 and $2200^{\circ} \mathrm{C}$ by Shahar et al. (2011) and Kempl et al. (2013a).

\section{Low-pressure experimental methods}

Kempl et al. (2013b) used an industrial-scale blast furnace to study $\mathrm{Si}$ isotopic behaviour during metal-silicate segregation at low pressure. Industrial-scale hot-metal alloy-producing blast furnaces are used for metal-silicate segregation as a first-step process during steel making. Blast furnaces reach a height of several tens of metres and have a diameter $>10 \mathrm{~m}$ at their widest point. They are loaded with a burden consisting of natural iron ores (commonly banded iron formations), de-volatised coal, and sinter and pellet materials that are industrially preenriched in iron silicates. By controlling oxygen fugacity and temperature in the belly of a blast furnace, hot iron metal is segregated from iron ore, sinter and pellets at high-temperature conditions, and oxygen fugacities close to the iron-wuestite (IW) buffer (Eugster \& Wones, 1962).

Kempl et al. (2013b) obtained coexisting metal and silicate samples produced in a blast furnace at Tatasteel IJmuiden, the Netherlands. After the metal was segregated from the iron ore, both hot metal and silicate slag were tapped and could be sampled for investigation after quenching. The temperatures 


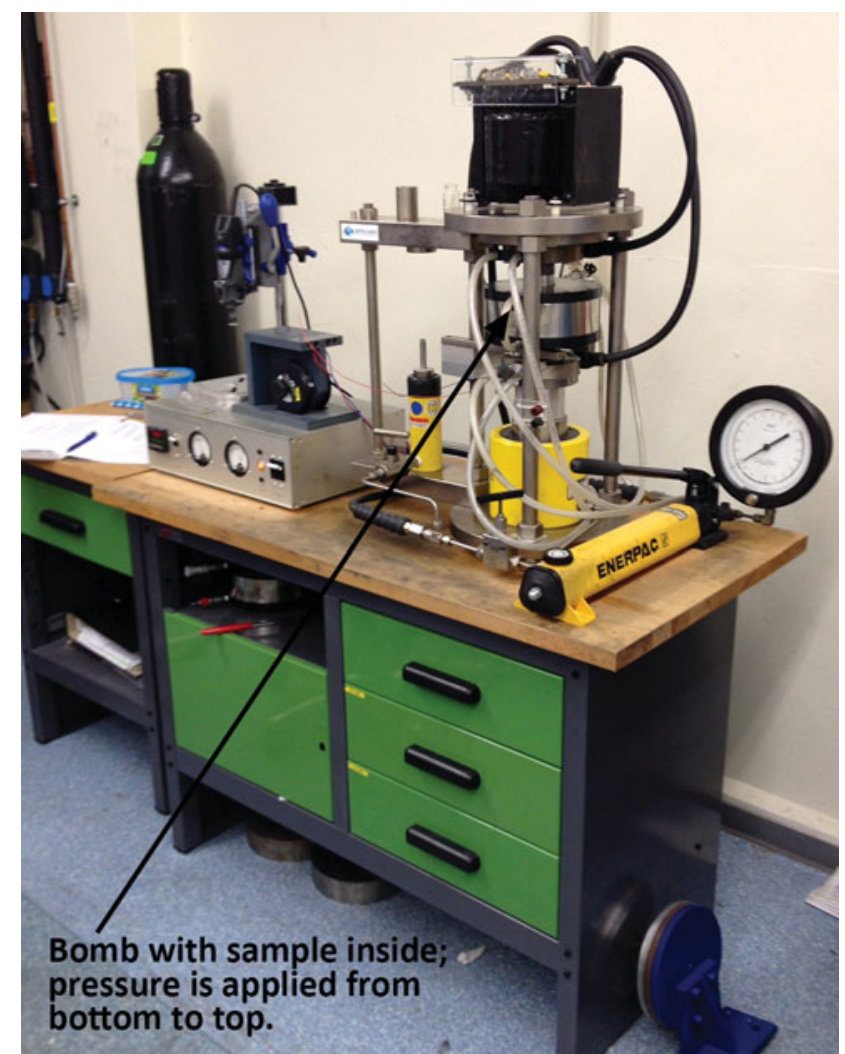

Fig. 6. The quick-press piston-cylinder (Depth of the Earth Department type) at the HPT laboratories of VU University Amsterdam. For calibration and setup see, for example, Rai et al. (2013). of these sample sets ranged between 1400 and $1600^{\circ} \mathrm{C}$ during sampling, whereas oxygen fugacities were close to the IW buffer. In the belly of the blast furnace temperatures were likely higher but can only be estimated to range between 1500 and $2400^{\circ} \mathrm{C}$

\section{Starting materials and compositions}

A compilation of starting materials, the nature of the samples and experimental conditions is given in Table 1.

Shahar et al. $(2009,2011)$ used experiments containing iron metal with $9 \mathrm{wt} \% \mathrm{Si}$ and an oxide mixture simulating a BSE composition. The metal phase in their run products typically contained $\sim 8 \mathrm{wt} \% \mathrm{Si}$ (Shahar et al., 2009). The silicate run product was partially molten, containing both solid olivine grains and quenched melt (Shahar et al., 2011). In both Shahar et al. study an $\mathrm{Si}$ isotope spike was added to the silicate starting material (Shahar et al., 2008) in order to track temporal changes in $\mathrm{Si}$ isotope fractionation and assess when isotopic equilibrium was reached. The experimental run duration was up to 60 minutes.

Ziegler et al. (2010) investigated the Si isotope fractionation between metal and silicate in two aubrite meteorites that contain Si-bearing metal phases. The silicate composition is given by mineral abbreviations in Table 1. In Ziegler et al. (2010) a detailed explanation of the chemical composition of the metal and silicate phases of the meteorites is given.

In the blast furnace study (Kempl et al., 2013b) coexisting hot-metal alloy and silicate glasses of a melilitic composition were sampled. The hot-metal alloy commonly contained
A)

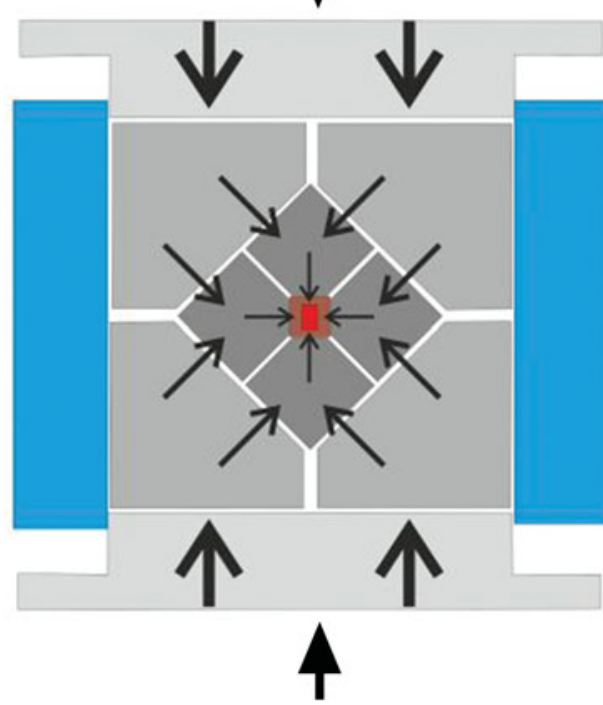

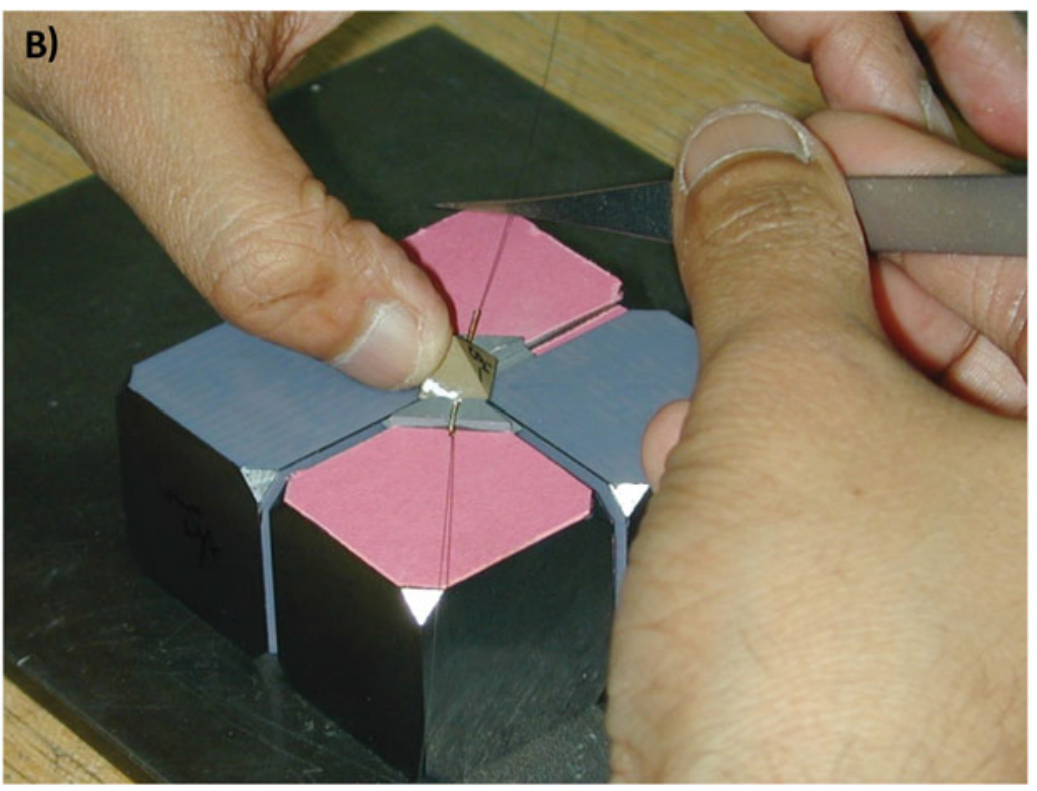

Fig. 7. In a multi-anvil press pressure is also applied hydraulically. A. Sets of first-and second-stage anvils surround the sample assembly so pressure is distributed equally from all sides (http://www.geopetro.ethz.ch/facilities/experimental/multi_anvil); B. The assembly is located in the centre of an octahedron together with a thermocouple. The octahedron is placed between eight tungsten-carbide cubes (first-stage anvils). Paper and tape are used for insulation to ensure constant and controlled heating (photograph by BGI Bayreuth). 


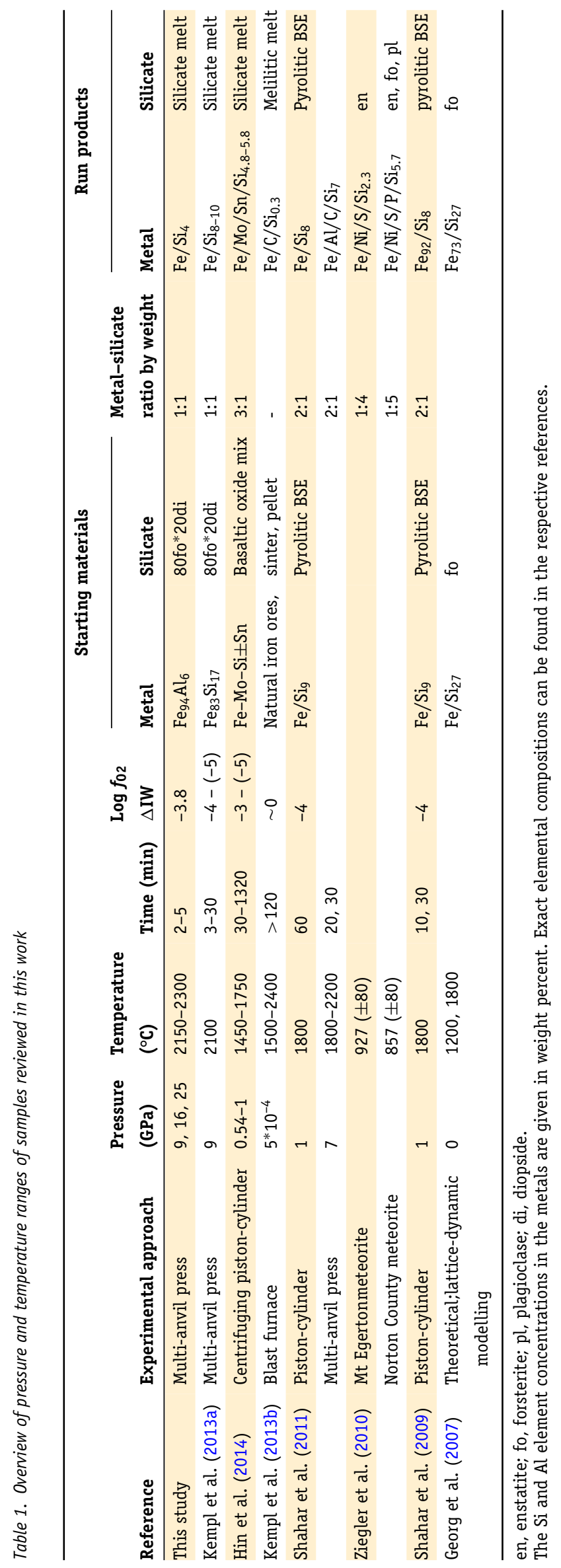

0.3-0.5 wt\% $\mathrm{Si}$, while the silicate contained $\mathrm{SiO}_{2}$ concentrations between 33.7 and $35.1 \mathrm{wt} \%$.

Hin et al. (2014) made use of different basaltic oxide mixtures combined with either $\mathrm{Sn}$-rich or $\mathrm{Sn}$-free $\mathrm{Fe}+\mathrm{Si}+\mathrm{Mo}$ powder. Sn and Mo were added to lower the melting point of the metal and to enable complete melting at given experimental pressures (Table 1). Each experiment contained about $75 \mathrm{wt} \%$ metal powder and 25\% silicate. Experimental run times were 30, 90, 240 and 1320 minutes. The run products in Hin et al. (2014) were completely molten and consisted of a silicate melt and a metal alloy bearing between 4.7 and $5.8 \mathrm{wt} \% \mathrm{Si}$.

Kempl et al. (2013a) performed a time series at $9 \mathrm{GPa}$ and $2100^{\circ} \mathrm{C}$ in which the silicate consisted of $80 \mathrm{wt} \%$ forsterite (fo) and $20 \mathrm{wt} \%$ diopside (di) prepared from the major element oxides $\mathrm{SiO}_{2}, \mathrm{MgO}$ and $\mathrm{CaCO}_{3}$. The metal starting material was a Si-bearing metal alloy with $17 \mathrm{wt} \%$ silicon. With increasing experimental runtime this metal $\mathrm{Si}$ concentration decreased to 10.0 and $8.8 \mathrm{wt} \% \mathrm{Si}$ after 13 and 30 minutes, respectively. The $\mathrm{SiO}_{2}$ concentration in the silicate run products varied between 43.1 and 46.2 wt\% (Kempl et al., 2013a). The detailed experimental conditions of all sample sets considered in this work are summarised in Table 2.

\section{Si isotope analyses}

Silicon has three naturally occurring stable isotopes, ${ }^{28} \mathrm{Si},{ }^{29} \mathrm{Si}$ and ${ }^{30} \mathrm{Si}$. Their relative abundances are commonly measured using MC-ICPMS techniques. By using multiple detector systems several isotopes can be measured simultaneously (Fig. 8A). The flat-top intensity peaks enable precise isotope analyses (Fig. 8B). Si isotope variations for $\mathrm{Si}$ are, as for other stable isotope systems, reported in the common $\delta$ notation, in which the less common isotopes ${ }^{29} \mathrm{Si}$ and ${ }^{30} \mathrm{Si}$ are used to form the isotopic ratios over ${ }^{28} \mathrm{Si}$. The delta notations for $\delta^{30} \mathrm{Si}\left(\delta^{30} \mathrm{Si}=\right.$ $\left.\left[\left(\left({ }^{30} \mathrm{Si} /{ }^{28} \mathrm{Si}_{\text {sample }}\right) /\left({ }^{30} \mathrm{Si} /{ }^{28} \mathrm{Si}_{\text {standard }}\right)\right)-1\right] \times 1000[\% \mathrm{\%}]\right)$ and $\delta^{29} \mathrm{Si}$ $\left(\delta^{29} \mathrm{Si}=\left[\left(\left({ }^{29} \mathrm{Si} /{ }^{28} \mathrm{Si}_{\text {sample }}\right) /\left({ }^{29} \mathrm{Si} /{ }^{28} \mathrm{Si}_{\text {standard }}\right)\right)-1\right] \times 1000[\%]\right)$ are expressed in per mille deviation of a sample relative to a standard. The common NIST Si isotope standard is the Californian beach sand RM-8546 (formerly known as NBS-28).

The use of different ionisation techniques complicates direct comparisons between results obtained in different laboratories (e.g. see discussion in Hin et al., 2014). Even when comparing results that were obtained by using the same type of sample ionisation, the recent review by Savage et al. (2014) shows there are issues with the reported accuracy of some of the literature data on the Si isotope compositions. If not using laser ablation for sample ionisation, MC-ICPMS analyses require dissolving the Si-bearing phases and separating Si quantitatively from the other cations in solution. The different studies listed in Tables 1 and 2 use different sample digestion techniques, which were recently reviewed in Savage et al. (2014).

One problem faced by the community studying $\mathrm{Si}$ isotope fractionation between metal and silicate is the absence of an 
Table 2. Summary of Si metal-silicate isotope mass fractionation $\left(\Delta^{30} \mathrm{Si}_{\text {sil-met }}\right)$ data

\begin{tabular}{|c|c|c|c|c|c|c|c|}
\hline Sample ID & Sample type & $\begin{array}{l}\text { Pressure } \\
(\mathrm{GPa})\end{array}$ & $\begin{array}{l}\text { Temperature } \\
\left({ }^{\circ} \mathrm{C}\right)\end{array}$ & Time (min) & $\Delta^{30} \mathrm{Si}_{\text {sil-met }}$ & Uncertainty & Reference \\
\hline B. 05.12 & Multi-anvil & 9 & 2200 & 5.0 & 0.71 & $0.16\left(1_{\mathrm{SD}}\right)$ & This study \\
\hline B. $10.12^{*}$ & & 16 & 2300 & 2.7 & 1.26 & $0.12\left(1_{\mathrm{SD}}\right)$ & \\
\hline B.11.12 & & 25 & 2200 & 5.0 & 1.39 & $0.13\left(1_{\mathrm{SD}}\right)$ & \\
\hline B.12.12* & & 9 & 2150 & 3.0 & 1.27 & $0.08\left(1_{\mathrm{SD}}\right)$ & \\
\hline B. $01.12^{*}$ & Multi-anvil & 9 & 2100 & 3.0 & 0.43 & $0.11\left(1_{\mathrm{SD}}\right)$ & Kempl et al. (2013a) \\
\hline B. $02.12^{*}$ & & 9 & 2100 & 10.0 & 1.18 & $0.12\left(1_{\mathrm{SD}}\right)$ & \\
\hline B.04.12* & & 9 & 2100 & 13.0 & 0.96 & $0.07\left(1_{S D}\right)$ & \\
\hline B.06.12 & & 9 & 2150 & 30.0 & 0.97 & $0.13\left(1_{S D}\right)$ & \\
\hline RH27 & Rotating piston-cylinder & 1.0 & 1450 & 1320 & 1.49 & $0.08\left(1_{\mathrm{SE}}\right)$ & Hin et al. (2014) \\
\hline RH31* & & 0.93 & 1450 & 30 & 1.84 & $0.03\left(1_{\mathrm{SE}}\right)$ & \\
\hline RH32 & & 0.89 & 1450 & 90 & 1.38 & $0.07\left(1_{\mathrm{SE}}\right)$ & \\
\hline RH37 & & 0.84 & 1450 & 240 & 1.58 & $0.04\left(1_{\mathrm{SE}}\right)$ & \\
\hline RH58 & & 0.58 & 1750 & 90 & 1.15 & $0.05\left(1_{\mathrm{SE}}\right)$ & \\
\hline RH66 & & 0.63 & 1750 & 90 & 0.93 & $0.04\left(1_{\mathrm{SE}}\right)$ & \\
\hline RH65 & & 0.54 & 1750 & 90 & 1.27 & $0.03\left(1_{\mathrm{SE}}\right)$ & \\
\hline RH67* & & 0.64 & 1750 & 30 & 1.09 & $0.08\left(1_{\mathrm{SE}}\right)$ & \\
\hline BF-01 & Blast furnace & $5^{*} 10^{-4}$ & $1500-2400$ & $>120$ & 1.60 & $0.15\left(1_{S D}\right)$ & Kempl et al. (2013b) \\
\hline BF-02 & & & & & 0.69 & $0.11\left(1_{S D}\right)$ & \\
\hline BF-03 & & & & & 1.49 & $0.13(1 \mathrm{SD})$ & \\
\hline BF-04 & & & & & 0.89 & $0.11\left(1_{\mathrm{SD}}\right)$ & \\
\hline BF-05 & & & & & 0.89 & $0.17\left(1_{\mathrm{SD}}\right)$ & \\
\hline BF-06 & & & & & 1.18 & $0.11\left(1_{\mathrm{SD}}\right)$ & \\
\hline BF-07 & & & & & 0.91 & $0.12\left(1_{S D}\right)$ & \\
\hline PL613* & Multi-anvil & 7 & 2200 & 20 & 1.07 & $0.22\left(1_{\mathrm{SE}}\right)$ & Shahar et al. (2011) \\
\hline PC871 & & & 2000 & 30 & 1.52 & $0.12\left(1_{\mathrm{SE}}\right)$ & \\
\hline PR892 & Piston-cylinder & 1 & 1800 & 60 & 1.77 & $0.16\left(1_{\mathrm{SE}}\right)$ & \\
\hline Mt Egerton & Meteorite data & & $927( \pm 80)$ & & 5.21 & $0.10\left(1_{\mathrm{SE}}\right)$ & Ziegler et al. (2010) \\
\hline Norton County & & & $857( \pm 80)$ & & 5.69 & $0.10\left(1_{\mathrm{SE}}\right)$ & \\
\hline PC637* & Piston-cylinder & 1 & 1800 & 1 & 0.05 & $0.02\left(1_{\mathrm{SE}}\right)$ & Shahar et al. (2009) \\
\hline PC639* & & & & 10 & 1.43 & $0.05\left(1_{\mathrm{SE}}\right)$ & \\
\hline PC638 & & & & 30 & 1.87 & $0.08\left(1_{\mathrm{SE}}\right)$ & \\
\hline $\mathrm{PDOS}_{2000 \mathrm{~K}}$ & PDOS calculation & & $\sim 1800$ & & 3.1 & & Georg et al. (2007) \\
\hline $\mathrm{PDOS}_{1500 \mathrm{~K}}$ & & & $\sim 1200$ & & 1.6 & & \\
\hline
\end{tabular}

*Experiments that authors claim were not of sufficient length to yield full equilibration.

$\mathrm{SD}$, standard deviation, SE, standard error.

Due to the different ways of determining and reporting the analytical uncertainties, the error type is given in brackets.

international Si-bearing metal standard. This could be a major problem, especially as high $\mathrm{Fe} / \mathrm{Si}$ ratios in dissolved metal phases can lead to major interferences during analyses due to the formation of iron hydroxides (e.g. Fitoussi et al., 2009). If sample digestion and purification procedures work perfectly there should not be any iron in the sample solutions, but it is unclear if optimal purification is always achieved. An interlaboratory calibration of an Si-bearing metal standard is even more important when comparing data of samples introduced in an MC-ICPMS by laser ablation.

\section{Materials and methods: this study}

In the new experiments performed for this study (Table 1), the silicate starting composition consisted of $80 \mathrm{wt} \%$ fo and $20 \mathrm{wt} \%$ di, as in Kempl et al. (2013a). This silicate composition was chosen because it is completely molten at the experimental target pressure and temperature conditions. Instead of starting the experiment with some $\mathrm{Si}$ already in the metallic form, as was done in all previous experiments, we added $6 \mathrm{wt} \%$ metallic aluminium powder to pure iron metal powder (Table 1). The 

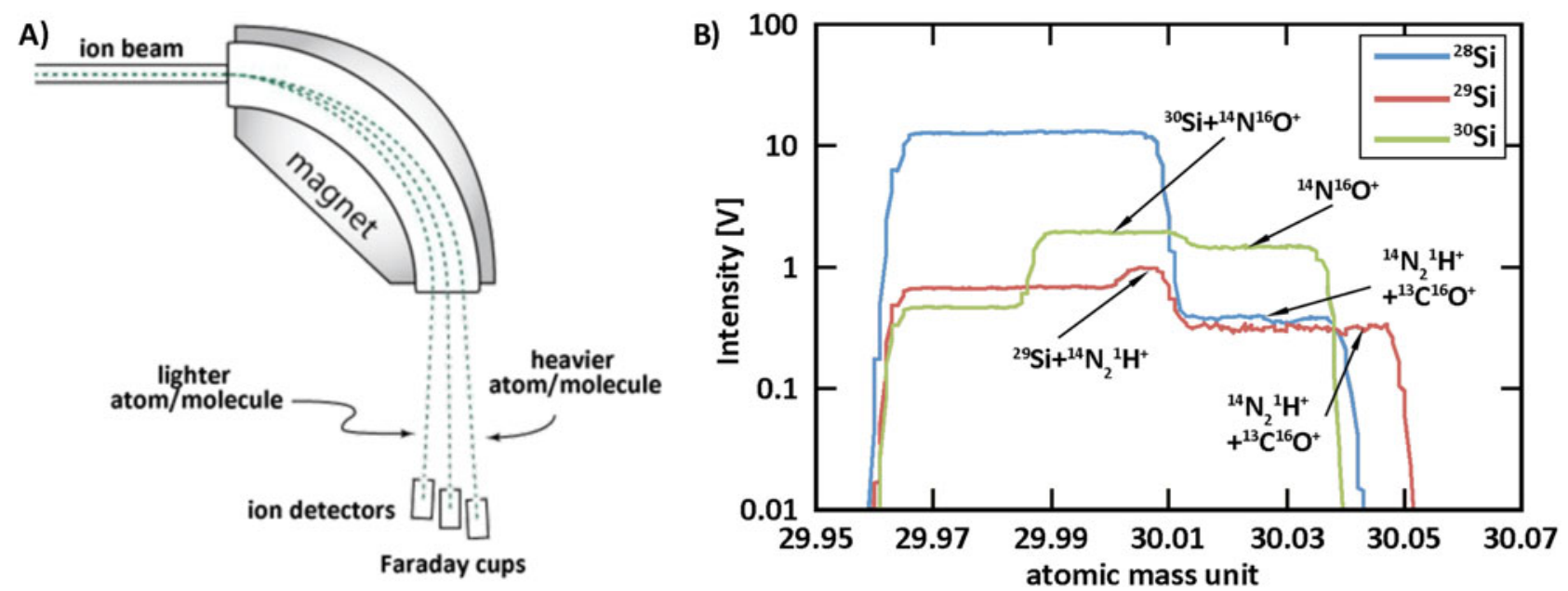

Fig. 8. A. Schematic of beam splitting in a multi-collector ICP-MS. With this technique eight to ten isotopes can be analysed simultaneously, depending on the machine set-up; B. Si has three stable isotopes that are analysed simultaneously on three different Faraday cups. The Si isotope signal is recorded at the centre of the interference-free peak plateau of all three isotopes, in this case at mass 29.975.

strategy here was to reduce the sample to such an extent that oxidised silicon from the silicate starting composition would reduce and partition into the metal phase. The silicate and metal starting materials were mixed mechanically in a metalsilicate 50:50 ratio by weight.

The new experiments were run in the 1200 and $5000 \mathrm{t}$ multianvil presses at the Bavarian Geo-Institute in Bayreuth, Germany. These presses are capable of running experiments at pressures up to $25 \mathrm{GPa}$ and temperatures up to $3000^{\circ} \mathrm{C}$. The pressure in the experiments was 9,16 or $25 \mathrm{GPa}$ at temperatures of $2150-2300^{\circ} \mathrm{C}$. We used capsules of $\mathrm{Mg} 0$ single crystals to avoid melting of a noble metal capsule, iron loss to the capsule material and noble metal contamination of our samples.

The chemical composition of the experimental sample charges was analysed by an electron probe microanalyser. The sample-containing part of the experimental assembly was embedded in epoxy after the experiment and polished down to the point of sample exposure. Fine polishing to a finish of less than $1 \mu \mathrm{m}$ was done using diamond paste (not silicon carbide) to avoid $\mathrm{Si}$ contamination.

Major element analyses of the experiments were performed on carbon-coated samples using a JEOL JXA-8800M electron probe at VU University Amsterdam, the Netherlands. Analyses were carried out by applying an acceleration voltage of $15 \mathrm{nA}$. A $10 \mu \mathrm{m}$ beam spot size was applied to metals and silicates. Natural fayalite, diopside, corundum and olivine were used as primary standards to quantify $\mathrm{Mg}, \mathrm{Ca}, \mathrm{Si}, \mathrm{Al}$ and $\mathrm{Fe}$. Metal analyses were carried out on a $\mathrm{FeSi}_{4}$ metal alloy. Data were corrected according to the ZAF algorithm (Reed, 2005). The typical accuracy of the analysed element concentrations was on the order of $2 \%$ relative.

After electron probe analysis, metal and silicate phases from each experiment were separated mechanically, dissolved and purified. The chemical sample digestion procedure was identi- cal to that reported in Kempl et al. (2013b). Atomic masses 28, 29 and 30 were collected simultaneously on the L4, L1 and C Faraday cups of the ThermoFinnigan Neptune MC-ICPMS at VU University Amsterdam, the Netherlands. The sample introduction system consisted of a Cetac Aridus I desolvating system containing an elemental Scientific PFA microcentric Aspire nebuliser system (dry plasma mode). A mass resolution of about $\mathrm{R}_{\text {Power }}=4300$ in high-resolution mode and of $\mathrm{R}_{\text {Power }}$ $=2500$ in medium resolution mode were sufficient (Van den Boorn et al., 2006) to resolve all Si isotopes from common polyatomic interferences. Secondary $\mathrm{Si}$ isotope standards included the Hawaiian basalt BHV0-2 and an in-house calibrated Si single crystal (Kempl, 2013).

\section{Results}

\section{Literature data}

The analysed $\delta^{30} \mathrm{Si}$ and $\delta^{29} \mathrm{Si}$ isotope signatures of silicates and coexisting metals from both literature studies and the new experiments are listed in Table 3. The $\delta^{30} \mathrm{Si}$ isotope signatures of silicates range between $-0.72 \%$ o $\left( \pm 0.05 \% ; 1_{S D}\right)$ and $0.21 \%$ ( \pm $\left.0.16 \% ; 1_{S D}\right)$, while the $\delta^{30} \mathrm{Si}$ of the metals varies from $-2.11 \%$ $\left( \pm 0.08 \% ; 1_{S D}\right)$ to $-0.85 \%$ o $\left( \pm 0.06 \% ; 1_{S D}\right)$. In addition, we report the average isotope signature of the samples PL613, PC871 and PR892 gathered by Shahar et al. (2011) by laser ablation. Because Ziegler et al. (2010) reports both solution work and laser ablation data, we list the $\delta^{30} \mathrm{Si}$ and $\delta^{29} \mathrm{Si}$ signatures of the sample pairs that we chose for this work. The analytical uncertainty in this table is either reported as one standard deviation $\left(1_{S D}\right)$ from the number of analyses (Kempl, 2013, this study; Shahar et al., 2011) or as one standard error (1 $1_{\mathrm{SE}}$ ) from the number of analyses (Ziegler et al., 2010). 
Table 3. Si isotope signatures of metals and silicates from HPT experiments plus the average Si isotope signatures from Shahar et al. (2011) and the two datasets from Ziegler et al. (2010)

\begin{tabular}{|c|c|c|c|c|c|c|c|c|}
\hline Sample ID & Material & $\mathrm{n}$ & Sample introduction & $\delta^{30} \mathrm{Si}(\% 0)$ & Uncertainty & $\delta^{29} \mathrm{Si}(\%)$ & Uncertainty & Reference \\
\hline BHVO-2 & Standard & 29 & Solution & -0.27 & 0.06 & -0.15 & 0.06 & Kempl (2013) \\
\hline Si single crystal & & 53 & & -2.61 & 0.12 & -1.32 & 0.08 & \\
\hline BHVO-2 & Standard & 5 & Solution & -0.26 & 0.07 & -0.15 & 0.05 & This study \\
\hline Si single crystal & & 7 & & -2.63 & 0.10 & -1.31 & 0.08 & \\
\hline \multirow[t]{2}{*}{ B. 05.12} & Silicate & 2 & Solution & -0.08 & 0.10 & -0.03 & 0.05 & This study \\
\hline & Metal & 3 & & -0.85 & 0.06 & -0.43 & 0.01 & \\
\hline \multirow[t]{2}{*}{ B.10.12 } & Silicate & 2 & & -0.22 & 0.09 & -0.10 & 0.01 & \\
\hline & Metal & 2 & & -1.49 & 0.09 & -0.67 & 0.04 & \\
\hline \multirow[t]{2}{*}{ B.11.12 } & Silicate & 2 & & -0.72 & 0.05 & -0.34 & 0.07 & \\
\hline & Metal & 2 & & -2.11 & 0.08 & -1.04 & 0.08 & \\
\hline \multirow[t]{2}{*}{ B.12.12. } & Silicate & 3 & & 0.21 & 0.16 & 0.15 & 0.05 & \\
\hline & Metal & 4 & & -1.04 & 0.15 & -0.51 & 0.14 & \\
\hline \multirow[t]{2}{*}{ PL613 } & Silicate & 8 & Laser ablation & -7.16 & 0.42 & -6.58 & 0.2 & Shahar et al. (2011) \\
\hline & Metal & 7 & & -8.23 & 0.43 & -7.22 & 0.2 & \\
\hline \multirow[t]{2}{*}{ PC871 } & Silicate & 15 & & -7.14 & 0.38 & -6.66 & 0.24 & \\
\hline & Metal & 7 & & -8.91 & 0.33 & -7.67 & 0.15 & \\
\hline \multirow[t]{2}{*}{ PR892 } & Silicate & 22 & & -6.92 & 0.43 & -6.59 & 0.22 & \\
\hline & Metal & 10 & & -8.44 & 0.22 & -7.39 & 0.09 & \\
\hline \multirow[t]{2}{*}{ Mt Egerton } & Silicate & 5 & Plasma & -0.73 & 0.32 & -0.37 & 0.16 & Ziegler et al. (2010) \\
\hline & Metal & 5 & & -5.93 & 0.16 & -3.08 & 0.08 & \\
\hline \multirow[t]{2}{*}{ Norton County } & Silicate & 30 & Laser ablation & -0.93 & 0.1 & -0.52 & 0.06 & \\
\hline & Metal & 4 & & -6.62 & 0.28 & -3.57 & 0.14 & \\
\hline
\end{tabular}

$n$, total number of analyses per sample material.

For this study and the data of Shahar et al. (2011) uncertainties are one external standard deviation from the number of analyses. Ziegler et al. (2010) uses one external standard error of the number of analyses.

The isotope fractionation between metal and silicate, $\Delta^{30} \mathrm{Si}_{\text {sil-met, }}$, is reported and summarised in Table 2. The silicatemetal isotope fractionation of this data collection varies from $0.05 \%$ o $\left( \pm 0.02 \%\right.$; $\left.1_{\mathrm{SE}}\right)$ for a 1 -minute piston-cylinder experiment by Shahar et al. (2009) at $1800^{\circ} \mathrm{C}$ and $1 \mathrm{GPa}$ up to $5.69 \%$ $\left( \pm 0.10 \% ; 1_{\mathrm{SE}}\right)$ and $5.21 \%$ o $\left( \pm 0.10 \% ; 1_{\mathrm{SE}}\right)$ in the natural samples of Ziegler et al. (2010) equilibrated in solid state over a couple of thousand years between $\sim 850$ and $\sim 930^{\circ} \mathrm{C}$. The analytical uncertainty in Table 2 is reported in terms of standard deviation or standard error, following the reporting in the individual studies.

\section{This study}

Fig. 9 shows a typical back-scattered electron image of the experimental run products. Both the silicate and metal phases melted completely during the experiments, and the metal phases all coalesced to segregate in spherical blebs that were easy to identify and easy to segregate from the silicate in preparation for dissolution.

Electron probe analyses show that after the experiments at 9, 16 and $25 \mathrm{GPa}$, no measurable $\mathrm{Al}$ is left in the metal phase, it has all oxidised. The $\mathrm{Si}$ concentration in the metals varies

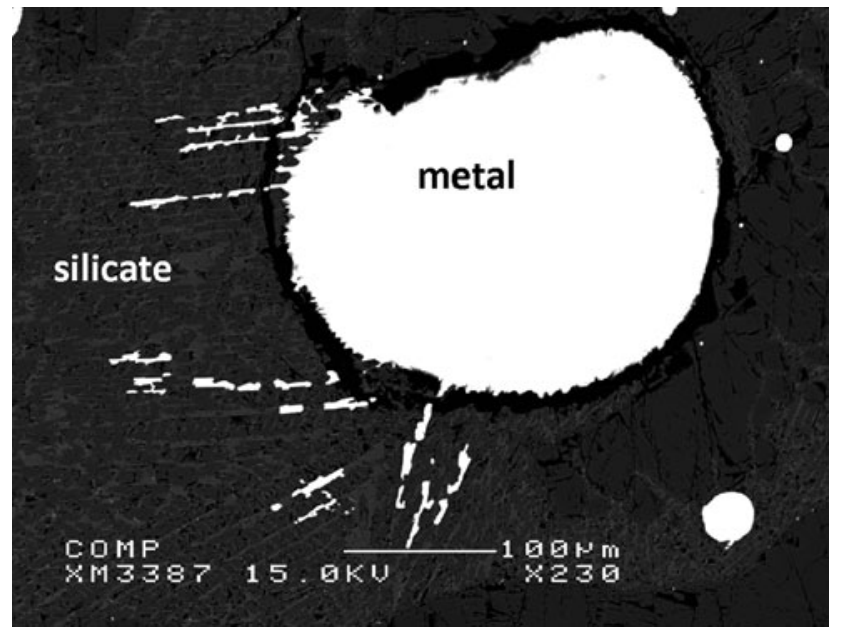

Fig. 9. Secondary electron image of experiment B.12.12. The quench texture in the silicate illustrates clearly that the silicate was completely molten at the experimental target conditions. The rounded shape of the metal indicates complete melting and merging of the metal at one ending of the capsule, after the starting materials were mixed mechanically in a metalsilicate 50:50 ratio by weight. 
Fig. 10. Three-isotope diagrams of investigated metal-silicate Si isotope fractionation. A. Experimental HT and HPT data of Kempl (2013) and Kempl et al. (2013); B. Experimental HPT data of Hin et al. (2014); C. Si isotope fractionation of two differentiated stoneiron meteorites (Ziegler et al., 2010); D. Experimental HPT data of Shahar et al. (2011). Data in $A, B$ and $C$ are plotted on the equilibrium fractionation line (dark) and kinetic fractionation line (light grey) for Si isotopes. Data in $D$ are plotted on a secondary fractionation line due to the application of an isotope spike technique to the three-isotope method in the experiments. In all experiments silicates provide the silicon reservoir and do not show a large scattering while incorporating the heavy $\mathrm{Si}$ isotope fraction. The metals concentrate on the light isotopes and show a large range of scattering due to isotope equilibration.
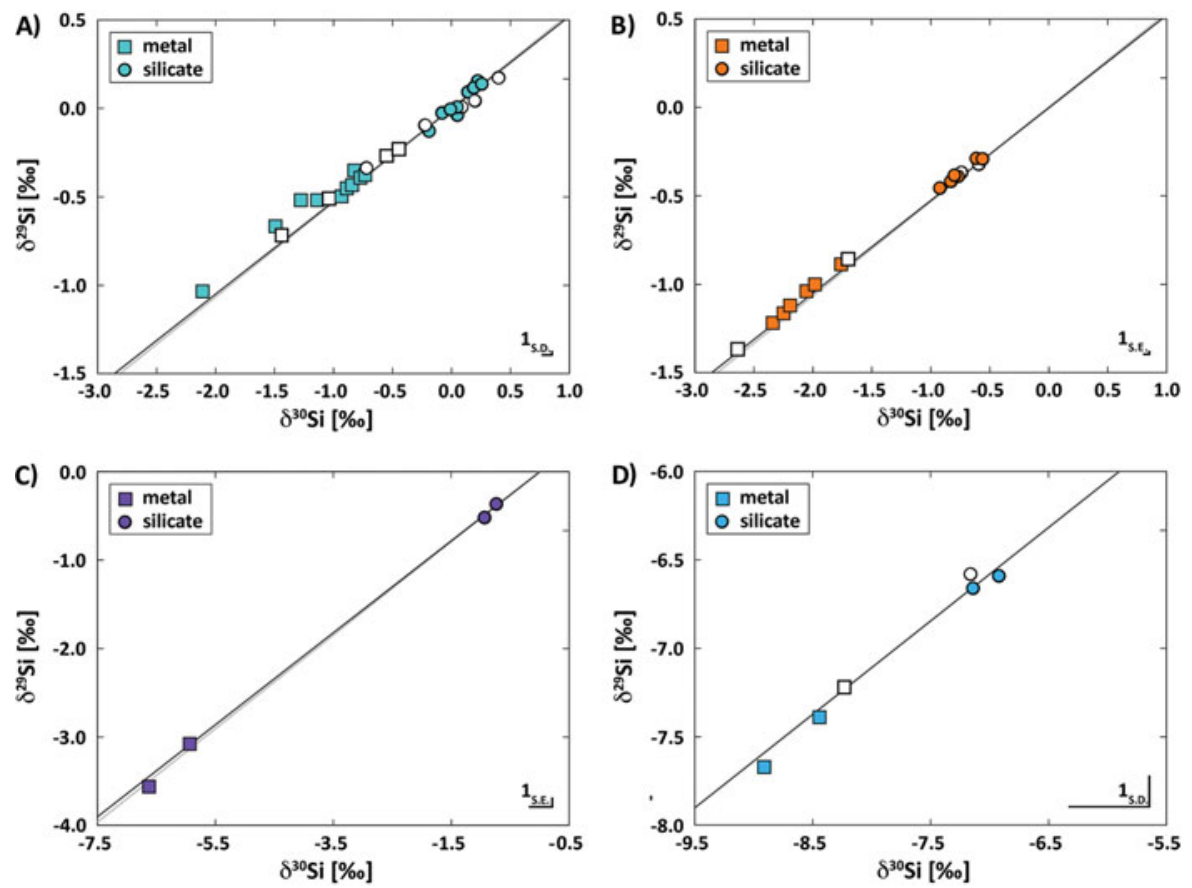

between 3.5 and $4.1 \mathrm{wt} \%$, depending on the experimental run time. The synthesised silicate melts contain $\mathrm{SiO}_{2}$ concentrations between 37.7 and $43.9 \mathrm{wt} \%$.

Standard data, the BHV0-2 basalt standard and the in-house Si single crystal standard were in good agreement with previously analysed data by Abraham et al. (2008), the compilations by Savage et al. (2014) and our own previously published data (Kempl, 2013).

Table 3 shows that the $\delta^{30} \mathrm{Si}$ of the silicate phases in the new experiments ranges between $-0.72 \pm 0.05 \%$ o $\left(1_{S D}\right)$ and $0.21 \pm$ $0.16 \%\left(1_{\mathrm{SD}}\right)$. Metals are depleted in the heavier $\mathrm{Si}$ isotopes compared to the silicates in each experiment, with $\delta^{30} \mathrm{Si}$ ranging between $-0.85 \pm 0.06 \%$ ( $\left.1_{\mathrm{SD}}\right)$ and $-2.11 \pm 0.08 \%$ ( $\left.1_{\mathrm{SD}}\right)$. $\Delta^{30} \mathrm{Si}_{\text {sil-met }}$ data for the new experiments (Table 2) vary in a narrow range between $0.71 \pm 0.16 \%$ o $\left(1_{S D}\right)$ and $1.39 \pm 0.13 \%$ $\left(1_{S D}\right)$. This range is within the total range of metal-silicate $\mathrm{Si}$ isotope fractionation data reported to date (Table 2) and appears to be consistent with equilibrated high-pressure samples from previous studies (Shahar et al., 2009, 2011; Kempl et al., 2013a; Hin et al., 2014).

\section{Three-isotope space for Si isotopes}

Theoretical calculations predicted that $\mathrm{Si}$ isotope fractionation is driven by the different chemical bonding environment of silicon. This assumption implies that a stiffer bonded phase, such as given in silicates, would concentrate the heavier $\mathrm{Si}$ isotopes, relative to a weaker bonded phase, such as occurs in metals (Georg et al., 2007; Schauble et al., 2007).

Figs $10 \mathrm{~A}-\mathrm{D}$ show the most recent data summary in the threeisotope space of Si from this study (Ziegler et al., 2010; Shahar et al., 2011; Kempl et al., 2013a,b; Hin et al., 2014). In all cases, silicates concentrate the heavier isotope fraction, metals the lighter fraction. This is consistent with the predictions of Georg et al. (2007) and Schauble et al. (2007). Consistent with mass balance considerations, the silicates provide an infinite $\mathrm{Si}$ isotope reservoir and do not show a wide scatter in $\mathrm{Si}$ isotopic composition, whereas the metals, which contain a much smaller fraction of the metal-silicate system Si budget, scatter over a wider range in order to equilibrate.

\section{Discussion}

\section{Si isotope fractionation between metal and silicate $\left(\Delta^{30}\right.$ Si $\left._{\text {sil-met }}\right)$}

In this study we present the results of metal-silicate partitioning experiments performed at pressures between 9 and $25 \mathrm{GPa}$ and temperatures between 2150 and $2300^{\circ} \mathrm{C}$. These are the highest experimental pressures applied in studies of $\mathrm{Si}$ isotope fractionation between metal and silicate. A comparison between these high-pressure data and existing lower-pressure data in terms of $\Delta^{30} \mathrm{Si}_{\text {sil-met }}$ is shown in Fig. 11.

Whether or not chemical and isotopic equilibrium was reached in the experiments is of primary concern. The experimental run time required for $\mathrm{Si}$ isotopic equilibration is still a matter of debate. Hin et al. (2014) showed that Si isotopic equilibrium is reached between 1.5 and 4 hours depending on the experimental temperature of 1750 or $1450^{\circ} \mathrm{C}$, respectively, at pressures between 0.54 and $1 \mathrm{GPa}$ in completely molten experiments. Shahar et al. (2011) suggest that isotope 


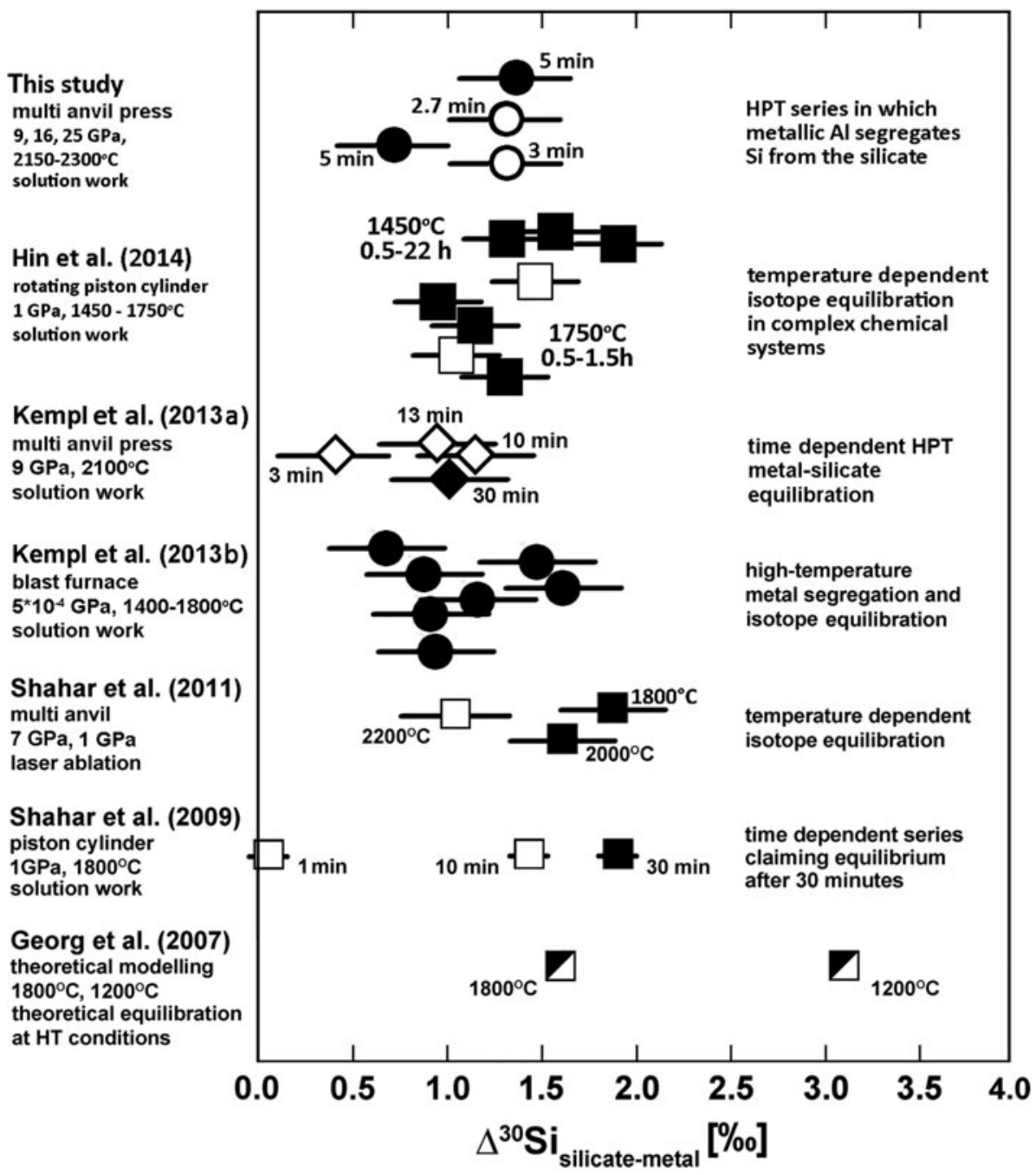

Fig. 11. Compilation of existing data for isotopic mass fractionation between metal and silicate; the sign of all data is positive. The variation of the data is still difficult to constrain. equilibration between metal and silicate is reached after $30 \mathrm{~min}$ utes at $1 \mathrm{GPa}$ and $1800^{\circ} \mathrm{C}$ in experiments in which the silicate was only partially molten. In Kempl et al. (2013a) Si metalsilicate isotope fractionation is identical within an acceptable error limit for experiments lasting 13 and 30 minutes at $9 \mathrm{GPa}$ and $2100^{\circ} \mathrm{C}$, whereas fractionation differs for shorter run durations. In the Kempl et al. (2013a) experiments, both silicate and metal phases were fully molten.

Although our new HPT experiments were run for relatively short times between 2.7 and 5 minutes, they reached $\Delta^{30} \mathrm{Si}_{\text {sil-met }}$ values that are consistent with previous high-pressure data run for significantly longer times (e.g. Hin et al., 2014; Kempl et al., 2013a). We have two explanations for this observation:

(1) At the very high temperatures of these experiments $\left(>2150^{\circ} \mathrm{C}\right)$, at which metal and silicate were both molten, isotopic equilibrium can be reached much faster than at the lower temperatures used in Shahar et al. (2011) and Hin et al. (2014).
(2) Because of the aluminium metal powder added to the iron metal starting material, we induced a speed-up of the chemical reaction for silicon to segregate from silicate and to partition into the metal compared to the $9 \mathrm{GPa}$ experiments of Kempl et al. (2013a). The direction of this reaction is opposite to the reaction occurring in earlier experimental studies in which the iron metal initially always contained a large amount of Si. Although the final equilibrated Si isotopic distribution should be independent of the reaction direction, the time it takes to reach this equilibrium could well differ.

\section{Temperature dependence of $\Delta^{30} \mathrm{Si}_{\text {sil-met }}$}

As is the case for any isotopic fractionation process, the $\mathrm{Si}$ isotopic fractionation between metal and silicate is dependent on temperature, with higher temperatures leading to values for $\Delta^{30} \mathrm{Si}_{\text {sil-met }}$ closer to zero. In Figs $12 \mathrm{~A}-\mathrm{C}$ we compare the temperature-dependent isotope fractionation between metal and silicate derived from Shahar et al. (2009, 2011), Ziegler 

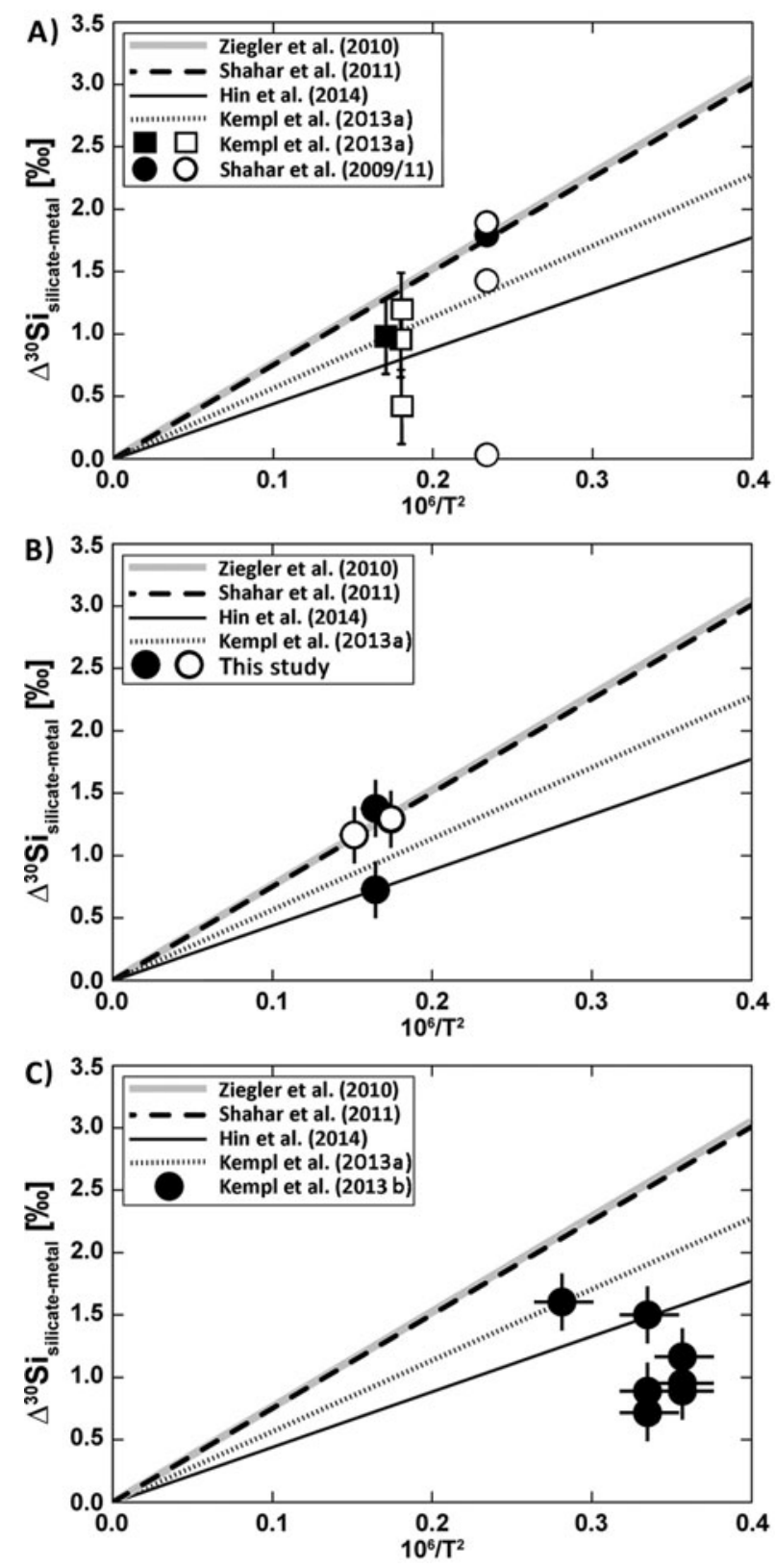

Fig. 12. Comparison of the temperature-dependent Si isotope fractionation between metal and silicate from different experimental studies. A. Timedependent studies in multi-anvil and piston-cylinder experiments (filled markers are equilibrated; empty markers are short-time experiments); $B$. Short-time experiments at HPT conditions $(9,16$ and $25 \mathrm{GPa}$ ) with a maximum run-time of 5 minutes scatter within error in the investigated field of equilibration. Experimental equilibration time scales are still a matter of debate; $C$. Blast furnace data had more than 120 minutes to equilibrate in the belly of the furnace. The occurrence of an SiC gaseous phase causes a dynamic equilibrium to occur and influences the isotope fractionation such that the majority of the data do not plot in the recent field of equilibrium isotope fractionation. et al. (2010), Hin et al. (2014) and Kempl et al. (2013a,b), exclusively using their own data points.

In Fig. 12A the temperature dependences previously obtained from experiments at $\sim 1,7$ and $9 \mathrm{GPa}$ (Shahar et al., 2009, 2011; Hin et al., 2014; Kempl et al., 2013a) are compared with each other. The data at 1 and 7 GPa of Shahar et al. (2009, 2011) show the largest isotope fractionation between metal and silicate, with values that are in good agreement with the natural sample data of the Mt Egerton and Norton County meteorites (Ziegler et al., 2010).

In contrast, the experimental data of Hin et al. (2014) obtained between 0.54 and $1 \mathrm{GPa}$ (Table 2) result in the smallest temperature dependence (Fig. 12A). Our own data previously gathered at $9 \mathrm{GPa}$ and $2100^{\circ} \mathrm{C}$ (Kempl et al., 2013a) result in a temperature dependence that lies between the dependencies derived from the Shahar et al. (2011) and Hin et al. (2014) experiments (Fig. 12A).

It is still matter of debate what is causing these apparent differences in temperature dependencies. We note that Shahar's silicate sample aliquots were partially molten (as shown in Shahar et al., 2011), consisting of mixtures of olivine grains and a silicate melt. A significant analytical isotope fractionation between silicate crystal and silicate melt was not observed by Shahar et al. (2011). However, both analytical work on larger, natural silicate samples and theoretical calculations of major element isotope fractionation have shown that isotope fractionation among silicate minerals does occur, and can reach several per mille variations depending on the crystalline structures and temperature of equilibration (e.g. Meheut et al., 2007, 2009; Polyakov, 2009; Huang et al., 2010, 2013). Recently, Meheut \& Schauble (2014) and Huang et al. (2014) theoretically calculated the silicon isotope fractionation between different silicate phases focusing on the role of the $\mathrm{Si}$ and $\mathrm{Si}-\mathrm{O}$ bonding environments.

Huang et al. (2014) investigated the expected Si isotope fractionation between mantle minerals at HPT conditions up to $25 \mathrm{GPa}$ and $3000 \mathrm{~K}$ theoretically. They show that silicatesilicate isotope fractionation decreases with increasing temperature and suggest that at the HPT conditions of the Shahar et al. (2011) experiments $S i$ isotope fractionation cannot be resolved analytically at present: the external analytical error on the MC-ICPMS is larger than the predicted isotope fractionation between two (or more) different silicates. We note that a small olivine-silicate melt fractionation of $\mathrm{Si}$ isotopes in the Shahar et al. (2011) experiments could provide an explanation for the relatively large external standard deviations in Shahar et al. (2011)'s silicates calculated in Table 3 from their laser-ablation analyses. Although a distinct difference between olivine and melt cannot be observed, the overall analytical uncertainty in the silicate $\mathrm{Si}$ isotope measurements reaches more than $0.2 \%$.

In contrast, the HPT experiments of Hin et al. (2014) and Kempl et al. (2013a) that are equilibrated and considered in 
Fig. 12A were completely molten, but have significantly different experimental target conditions in terms of pressure and temperature.

Fig. 12B shows the result of the experiments performed in this study, in the pressure range of 9-25 GPa. Overall, the new experimental data are consistent with the range of temperature dependencies previously suggested. Three data points, including the experiments at 16 and $25 \mathrm{GPa}$, plot on the temperature dependence derived by Shahar et al. (2009), whereas the experiment at $9 \mathrm{GPa}$ with an experimental duration of 5 minutes plots on the temperature dependence based on the experiments by Hin et al. (2014). There is no clear trend in $\Delta^{30} \mathrm{Si}_{\text {sil-met }}$ as a function of either temperature or run duration in these new experiments. Fig. 12B supports our hypothesis that despite the short run durations involved, our new experiments are consistent with full isotopic equilibration of Si between metal and silicate. This unexpected result suggests that starting with an Si-free metal in these experiments leads to faster equilibration than starting with an Si-rich metal. Finally, we note that the data in Fig. 12B suggest that the pressure effect on $\mathrm{Si}$ isotope fractionation between metal and silicate is minor, at least up to pressures of $25 \mathrm{GPa}$. If it were large a clear deviation of the 16 and $25 \mathrm{GPa}$ experimental data should have been observed.

Fig. 12C shows data that were obtained from sample sets of the industrial blast furnace (Kempl et al., 2013b). The majority of these data plot below the analysed temperature dependence of Hin et al. (2014). Because of the dynamic equilibrium in the $\mathrm{SiO}_{2}-\mathrm{SiC}-\mathrm{SiO}-\mathrm{Si}$ cycle within the blast furnace during steel making (Kempl et al., 2013b), the isotope fractionation between metal and silicate of these samples should be viewed critically. In addition, the error of the temperature of equilibration of these experiments is relatively large due to the imprecise temperature estimation during steel making.

It is important to note that regardless of which of the temperature dependencies shown in Fig. 12 is most applicable, the differences in $\Delta^{30} \mathrm{Si}_{\text {sil-met }}$ shown in Fig. 11 cannot only be explained by differences in temperature. Correcting all data to a common temperature still leads to major differences in $\Delta^{30} \mathrm{Si}_{\text {sil-met }}$ between, for example, the experiments at $1 \mathrm{GPa}$ performed by Shahar et al. $(2009,2011)$ and Hin et al. (2014). These differences are larger than any reasonable analytical uncertainty and must be related to differences in experimental and/or analytical approach or analytical technique, or differences in silicate and/or metal composition. An extensive discussion of the differences between the Shahar et al. (2009, 2011) and Hin et al. (2014) data at 1-7 GPa is provided in Hin et al. (2014) and we will not repeat the pros and cons of those studies here. Suffice to say that the discrepancy between these lower pressure data is not resolved by the addition of the highpressure data at 9-25 GPa from Kempl et al. (2013a) and this study. In this regard, we reiterate that the absence of an international Si-bearing metal standard makes it hard to compare metal Si isotope data obtained in different laboratories using different analytical techniques.

\section{Conclusions and outlook}

We have presented the results of new HPT experiments and combined these with a review of literature data to investigate how the $\mathrm{Si}$ isotope fractionation behaviour between metal and silicate varies as a function specifically of experimental run time and temperature. We show that although there is no debate about the sign of fractionation (with silicates isotopically heavier than metals), absolute values for $\mathrm{Si}$ isotope fractionation between metal and silicate remain difficult to constrain because the experimental database is sometimes contradictory and certainly incomplete. Si isotopic measurements of metals in particular suffer from the absence of a true inter-laboratory comparison.

We conclude that although individual studies have used their measured metal-silicate fractionation of $\mathrm{Si}$ isotopes to derive constraints on the amount of $\mathrm{Si}$ in the core of the Earth, there is little agreement between different studies and it remains unclear what causes the disagreement. In order to derive accurate quantitative estimates of the $\mathrm{Si}$ content of the core of the Earth or other planets, we suggest that a wide range of additional experiments and analyses will be required.

First, not a single experiment exists that has been analysed by different laboratories. To increase the fidelity of the community's results, large-volume experiments should be performed with the resulting sample charges distributed to several laboratories. This would address any differences in analytical approaches and analytical techniques, in particular with respect to the $\mathrm{Si}$ isotopic composition determinations of metal phases. In parallel, an inter-laboratory comparison of a metal $\mathrm{Si}$ isotopic standard should be set up.

Second, experiments that assess the extent of Si isotopic fractionation between different silicate phases at high pressure and high temperature are required to assess their effect on the existing metal-silicate fractionation database. Third, single laboratories should explore specifically the effects of pressure, temperature and silicate composition on $\mathrm{Si}$ isotope fractionation. Studies published to date, including our own, are based on a very small set of experiments that typically do not enable perfect isolation of individual parameters such as temperature or pressure on fractionation.

\section{Acknowledgments}

We thank two anonymous reviewers for their extensive comments which significantly improved the manuscript. The MCICPMS facility at VU University Amsterdam is funded by the Dutch Organisation for Scientific Research (NWO) by grant no. 
175.107.404.01. This study was funded by NWO User Support Programme Planetary Science grant G0-PL/08 to P.Z.V.

\section{References}

Abraham, K., Opfergelt, S., Fripiat, F., Cavagna, A.-J., de Jong, J.T.M., Foley, S.F., André, L. \& Cardinal, D., 2008. $\delta^{30} \mathrm{Si}$ and $\delta^{29} \mathrm{Si}$ determination on USGS BHVO-1 and BHVO-2 reference materials with a new configuration on a NU plasma multi-collector ICP-MS. Geostandards and Geoanalytical Research 32: 193-202.

Allègre, C.J., Poirier, J.-P., Humler, E. \& Hofmann, A.W., 1995. The chemical composition of the Earth. Earth and Planetary Science Letters 134: 515-526.

Anderson, O.L. \& Isaak, D.G., 2002. Another look at the core density deficit of the Earth's outer core. Physics of Earth and Planetary Interiors 131: 19-27.

Armytage, R.M.G., Georg, R.B., Savage, P.S., Williams, H.M. \& Halliday, A.N., 2011. Silicon isotopes in meteorites and planetary core formation. Geochimica et Cosmochimica Acta 75: 3662-3676.

Armytage, R.M.G., Georg, R.B., Williams, H.M. \& Halliday, A.N. 2012: Silicon isotopes in lunar rocks: Implications for the Moon's formation and the early history of the Earth. Geochimica et Cosmochimica Acta 77: 504-514.

Badro, J., Côté, A.S. \& Brodholt, J.P., 2014. A seismologically consistent compositional model of Earth's core. Proceedings of the National Academy of Sciences 111: 7542-7545.

Birch, $\boldsymbol{F} ., 1952$. Elasticity and constitution of the Earth's interior. Journal of Geophysical Research 57: 227-286.

Birch, $\boldsymbol{F} ., 1964$. Density and composition of mantle and core. Journal of Geophysical Research 69: 4377-4388.

Boyd, F.R. \& England, J.L., 1960. Apparatus for phase-equilibrium measurements at pressures up to 50 kilobars and temperatures up to $1750^{\circ} \mathrm{C}$. Journal of Geophysical Research 65: 741-748.

Brett, R., 1984. Chemical equilibration of the Earth's core and upper mantle. Geochimica et Cosmochimica Acta 48: 1183-1188.

Burkhardt, C., Kleine, T., Bourdon, B., Palme, H., Zipfel, J., Friedrich, J.M. \& Ebel, D.S., 2008. Hf-W mineral isochron for $\mathrm{Ca}, \mathrm{Al}$-rich inclusions: Age of the solar system and the timing of core formation in planetesimals. Geochimica et Cosmochimica Acta 72: 6177-6197.

Chakrabarti, R. \& Jacobson, S.B., 2010. Silicon isotopes in the inner Solar System: Implications for core formation, solar system processes and partial melting. Geochimica et Cosmochimica Acta 74: 6921-6933.

Chambers, J.E., 2004. Planetary accretion in the inner Solar System. Earth and Planetary Science Letters 223: 214-252.

Corgne, A., Siebert, J. \& Badro, J., 2009: 0xygen as a light element: A solution to single stage core formation. Earth and Planetary Science Letters 288: 108114.

Dasgupta, R. \& Walker, D., 2008. Carbon solubility in core melts in a shallow magma ocean environment and distribution of carbon between the Earth's core and the mantle. Geochimica et Cosmochimica Acta 72: 4627-4641.

Douthitt, C.B., 1982. The geochemistry of the stable isotopes of silicon. Geochimica et Cosmochimica Acta 46: 1449-1458.

Drake, M.J. \& Righter, K., 2002. Determining the composition of the Earth. Science 416: 39-44.

Dreibus, G. \& Palme, H., 1996. Cosmochemical constraints on the sulfur content in the Earth's core. Geochimica et Cosmochimica Acta 60: 1125-1130.
Dumberry, M. \& Rivoldini, A., 2014. Mercury's inner core size and corecrystallization regime. Icarus 248: 254-268.

Elkins-Tanton, L.T., 2012. Magma 0ceans in inner solar systems. Annual Review of Earth and Planetary Sciences 40: 113-139.

Eugster, H.P. \& Wones, D.R., 1962. Stability relations of the ferruginous biotite, annite. Journal of Petrolology 3: 82-125.

Fitoussi, C. \& Bourdon, B., 2012. Silicon isotope evidence against an enstatite chondrite earth. Science 335: 1477-1480.

Fitoussi, C., Bourdon, B., Kleine, T., Oberli, F. \& Reynolds, B.C., 2009. Si isotope systematics of meteorites and terrestrial peridotites: implications for $\mathrm{Mg} / \mathrm{Si}$ fractionation in the solar nebula and for $\mathrm{Si}$ in the Earth's core. Earth and Planetary Science Letters 287: 77-85.

Georg, R.B., Halliday, A.N., Schauble, E.A. \& Reynolds, B.C., 2007. Silicon in the Earth's core. Nature 447: 1102-1106.

Gessmann, C.K., Wood, B.J., Rubie, D.C. \& Kilburn, M.R., 2001. Solubility of silicon in liquid metal at high pressure: implications for the composition of the Earth's core. Earth and Planetary Science Letters 184: 367376.

Gutenberg, B., 1914. Über Erdbebenwellen VIIA. Königliche Gesellschaft der Wissenschaftlichen Nachrichten Heft 2, 125-177.

Halliday, A.N., 2004. Mixing, volatile loss and compositional change during impact-driven accretion of the Earth. Nature 427: 505-509.

Hin, R.C., Fitoussi, C., Schmidt, M.W. \& Bourdon, B., 2014. Experimental determination of the $\mathrm{Si}$ isotope fractionation factor between liquid metal and liquid silicate. Earth and Planetary Science Letters 387: 55-66.

Huang, S., Farkaš, J. \& Jacobsen, S.B., 2010. Calcium isotopic fractionation between clinopyroxene and orthopyroxene from mantle peridotites. Earth and Planetary Science Letters 292: 337-344.

Huang, F., Chen, L., Wu, Z. \& Wang, W., 2013. First-principles calculations of equilibrium $\mathrm{Mg}$ isotope fractionations between garnet, clinopyroxene, orthopyroxene, and olivine: implications for $\mathrm{Mg}$ isotope thermometry. Earth and Planetary Science Letters 367: 61-70.

Huang, F., Wu, Z., Huang, S. \& Wu, F., 2014. First-principles calculations of equilibrium silicon isotope fractionation among mantle minerals. Geochimica and Cosmochimica Acta 140: 509-520.

Inaba, S., Tanaka, H., Nakazawa, K., Wetherill, G.W. \& Kokubo, E., 2001. High-accuracy statistical simulation of planetary accretion: II. Comparison with N-body simulation. Icarus 149: 253-250.

Javoy, M., 1999. Chemical earth models. Comptes Rendus de l'Académie des Sciences - Series IIA. Earth and Planetary Science 329: 537-555.

Jeffreys, H., 1935. The surface waves of earthquakes. Monthly Notes of the Royal Astronomical Society, Geophysical Supplement 3: 253-261.

Kempl, J., 2013. From Earth's Building Blocks to Metallic Planetary Cores - A Combined Si Stable Isotope Geochemistry and HPT Experimental Study. PhD thesis. Solid Earth Print Production (Berlin, Amsterdam).

Kempl, J., Frost, D.J., Vroon, P.Z., Kowalski, P.M. \& van Westrenen, W., 2013a. Silicon isotope fractionation between metal and silicate at high pressure and high temperature - Implications for Earth's core. Lunar and Planetary Science Conference 44, abstract 1891.

Kempl, J., Vroon, P.Z., Zinngrebe, E. \& van Westrenen, W., 2013b. Si isotope fractionation between Si-poor metal and silicate melt at pressure-temperature conditions relevant to metal segregation in small planetary bodies. Earth and Planetary Science Letters 368: 61-68. 
Kilburn, M.R. \& Wood, B.J., 1997. Metal-silicate partitioning and the incompatibility of $S$ and Si during core formation. Earth and Planetary Science Letters 152: $139-148$.

Knibbe, J.S. \& van Westrenen, W., 2015. Interior configuration models for planet Mercury incorporating planetary contraction constraints. Journal of Geophysical Research: Planets 120: 1904-1920.

Kortenkamp, S.J., Wetherill, G.W. \& Inaba, S., 2001. Runaway growth of planetary embryos facilitated by massive bodies in a protoplanetary disk. Science 293: 1127-1129.

Li, F. \& Fei, Y., 2003. Experimental constraints on core composition. In: Carlson, R.W. (ed): The Mantle and Core. Elsevier (Amsterdam).

Lodders, $K ., 2003$. Solar system abundances and condensation temperatures of the elements. Astrophysical Journal 591: 1220-1247.

MacDonald, G.J.F. \& Knopoff, L., 1958. On the chemical composition of the outer core. Geophysical Journal I: 284.

Malavergne, V., Siebert, J., Guyot, F., Gautron, L., Combes, R., Hammouda, T., Borensztan, S., Frost, D. \& Martinez, I., 2004. Si in the core? New high-pressure and high-temperature experimental data. Geochimica et Cosmochimica Acta 68: 4201-4211.

McDonough, W.F., 2003. Compositional model 664 for the Earth's core. Treatise on Geochemistry 2: 547-568.

McDonough, W.F. \& Sun, S.S., 1995. The composition of the Earth. Chemical Geology 120: 223-253.

Méheut, M. \& Schauble, E.A., 2014. Silicon isotope fractionation in silicate minerals: insights from first-principles models of phyllosilicates, albite and pyrope. Geochimica et Cosmochimica Acta 134: 137-154.

Méheut, M., Lazzeri, M., Balan, E. \& Mauri, F., 2007. Equilibrium isotopic fractionation in the kaolinite, quartz, water system: prediction from firstprinciples density-functional theory. Geochimica et Cosmochimica Acta 71: 3170-3181.

Méheut, M., Lazzeri, M., Balan, E. \& Mauri, F., 2009. Structural control over equilibrium silicon and oxygen isotopic fractionation: a first-principles densityfunctional theory study. Chemical Geology 258: 28-37.

Molini-Velsko, C., Mayeda, T.K. \& Clayton, R.N., 1986. Isotopic composition of silicon in meteorites. Geochimica et Cosmochimica Acta 50: 2719-2726.

Okuchi, T., 1997: Hydrogen partitioning into molten iron at high pressure: Implications for Earth's Core. Science 278: 1781-1784.

Oldham, R.D., 1906. Constitution of the interior of the Earth as revealed by earthquakes. Quarterly Journal of the Geological Society 62: 456-475.

Poirier, J.P., 1994. Light elements in the Earth's outer core: A critical review. Physics of Earth and Planetary Interiors 85: 319-337.

Polyakov, V.B., 2009. Equilibrium iron isotope fractionation at core-mantle boundary conditions. Science 323: 912-914.

Rai, N. \& Van Westrenen, W., 2013. Core-mantle differentiation in Mars. Journal of Geophysical Research: Planets 118: 1195-1203.

Rai, N. \& Van Westrenen, W., 2014. Lunar core formation: New constraints from metal-silicate partitioning of siderophile elements. Earth and Planetary Science Letters 388: 343-352.

Rai, N., Ghosh, S., Wälle, M. \& Van Westrenen, W., 2013. Quantifying the effect of solid phase composition and structure on solid-liquid partitioning of siderophile and chalcophile elements in the iron-sulfur system. Chemical Geology 357: 85-94.
Reed, S.J.B., 2005. Electron Microprobe Analysis and Scanning Electron Microscopy in Geology. Cambridge University Press (Cambridge).

Ricolleau, A., Fei, Y., Corgne, A., Siebert, J. \& Badro, J., 2011. 0xygen and silicon contents of Earth's core from high-pressure metal-silicate partitioning experiments. Earth and Planetary Science Letters 310: 409421.

Ringwood, A.E., 1966. Chemical evolution of the terrestrial planets. Geochimica et Cosmochimica Acta 30: 41-104.

Rubie, D.C., Melosh, H.J., Reid, J.E., Liebske, C. \& Righter, K., 2003. Mechanisms of metal-silicate equilibration in the terrestrial magma ocean. Earth and Planetary Science Letters 205: 239-255.

Savage, P.S. \& Moynier, F., 2013. Silicon isotopic variation in enstatite meteorites: Clues to their origin and Earth-forming material. Earth and Planetary Science Letters 361: 487-496.

Savage, P.S., Georg, R.B., Armytage, R.M.G., Williams, H.M. \& Halliday, A.N., 2010. Silicon isotope homogeneity in the mantle. Earth and Planetary Science Letters 295: 139-146.

Savage, P.S., Armytage, R.M.G., Georg, R.B. \& Halliday, A.N., 2014. High temperature silicon isotope geochemistry. Lithos 190-191: 500519.

Schauble, E.A., Méheut, M. \& Hill, P.S., 2007. Combining metal stable isotope fractionation theory with experiments. Elements 5: 369-374.

Schmidt, M.W., Conolly, J.A.D., Günther, D. \& Bogaerts, M., 2006. Element partitioning: the role of melt structure and composition. Science 312: 16461650.

Shahar, A., Young, E.D. \& Manning, C.E., 2008. Equilibrium hightemperature $\mathrm{Fe}$ isotope fractionation between fayalite and magnetite: an experimental calibration. Earth and Planetary Science Letters 268: 330-338.

Shahar, A., Ziegler, K., Young, E.D., Ricolleau, A., Schauble, E.A. \& Fei, Y., 2009. Experimentally determined $\mathrm{Si}$ isotope fractionation between silicate and Fe metal and implications for Earth's core formation. Earth and Planetary Science Letters 288: 228-234.

Shahar, A., Hillgren, V.J., Young, E.D., Fei, Y., Macris, C. \& Deng, L., 2011. High-temperature $\mathrm{Si}$ isotope fractionation between iron metal and silicate. Geochimica et Cosmochimica Acta 75: 7688-7697.

Steenstra, E.S., Knibbe, J.S., Rai, N. \& Van Westrenen, W., 2015. Constraints on core formation in Vesta from metal-silicate partitioning of siderophile elements. Earth and Planetary Science Letters 177: 48-61.

Stevenson, D.J., 1990. Fluid dynamics of core formation. In: Newsom, H. \& Jones, J.H. (eds): The origin of the Earth. 0xford University Press (London): 231249.

Tuff, J., Wood, B.J. \& Wade, J., 2011. The effect of Si on metal-silicate partitioning of siderophile elements and implications for the conditions of core formation. Geochimica et Cosmochimica Acta 75: 673-690.

Van den Boorn, S.H.J.M., Vroon, P.Z., van Belle, C.C., van der Wagt, B., Schwieters, J. \& van Bergen, M.J., 2006. Determination of silicon isotope ratios in silicate materials by high-resolution MC-ICPMS using a sodium hydroxide sample digestion method. Journal of Analytical Atomtic Spectrometry 21: 734-742.

Wade, J. \& Wood, B.J., 2005 Core formation and the oxidation state of the earth. Earth and Planetary Science Letters 236: 78-95. 
Walker, D., Carpenter, M.A. \& Hitch, C.M., 1990. Some simplifications to multianvil devices for high-pressure experiments. American Mineralogist 75: 10201028.

Wetherill, G.W., 1985. Occurrence of giant impacts during the growth of the terrestrial planets. Science 228: 887-879.

Wood, B.J., 1993. Carbon in the core. Earth and Planetary Science Letters 117: 593-607.

Wood, B.J. \& Halliday, A.N., 2005. Cooling of the Earth and core formation after the Giant Impact. Nature 437: 1345-1348.
Yin, Q., Jacobsen, S.B., Yamashita, K., Blichert-Toft, J., Télouk, P. \& Albarède, F., 2002. A short timescale for terrestrial planet formation from Hf-W chronometry of meteorites. Nature 418: 494-955.

Yoshino, T., Walter, M.J. \& Katsura, T., 2003. Core formation in planetesimals triggered by permeable flow. Nature 422: 154-157.

Ziegler, K., Young, E., Schauble, E.A. \& Wasson, T.J., 2010. Metal-silicate silicon isotope fractionation in enstatite meteorites and constraints on Earth's core formation. Earth and Planetary Science Letters 295: 487496. 